\title{
La arquitectura urbana de Idanha-a-Velha (Portugal) en el contexto de la Lusitania en la Antigüedad tardía
}

\author{
Urban architecture in Idanha-a-Velha (Portugal) \\ in the context of Late Antique Lusitania
}

\author{
ISABEL SÁNCHEZ RAMOS \\ University College London. Institute of Archaeology \\ 31-34 Gordon Square, London, WC1H OPY, UK \\ i.sanchez@ucl.ac.uk
}

Este artículo analiza los principales edificios y estructuras que dieron forma al paisaje tardoantiguo de la ciuitas Igaeditaronum (Idanha-a-Velha, Portugal), en el marco de los modelos constructivos y urbanísticos de la arquitectura de la Lusitania romana tardía. En el área conocida como Paço dos Bispos se documenta un complejo episcopal significativo del siglo vi integrado por varios edificios, que está bien preservado y rodeado por la muralla bajoimperial. Desde 2016, el objetivo de esta investigación ha sido realizar un estudio multidisciplinario para analizar el paisaje urbano egitano mediante el registro de los datos arqueológicos disponibles y la aplicación de tecnologías de teledetección a la evidencia material. El estudio estratigráfico de los muros en algunos edificios ha permitido identificar la planta original de la estructura episcopal de otros añadidos constructivos posteriores, así como definir las características técnicas específicas que se utilizaron. La finalidad de este trabajo es intentar comprender paralelamente la evolución de la arquitectura de poder, tanto civil como eclesiástica, las continuidades y los cambios detectados en los patrones arquitectónicos urbanos de la antigua Lusitania. Finalmente, el propósito es explicar el factor cultural, la naturaleza social, económica e ideológica de las murallas, iglesias, episcopia, palacios, etc., estudiando las técnicas constructivas, los materiales y las diferentes etapas cronológicas. Como Emerita Augusta, Egitania ilustra perfectamente la interacción entre el poder local episcopal y la monarquía visigoda asentada en Toledo a través de la presencia de algunos de los componentes esenciales del paisaje urbano (muralla y arquitectura de prestigio), la vigencia de la comunicación terrestre, y las fuentes económicas y de riqueza del obispado, que se basaron sobre todo en la explotación de los recursos naturales del territorio. 
This paper will analyse the main buildings and urban structures that shaped the late antique landscape of the ciuitas Igaeditaronum (Idanha-a-Velha, Portugal), in the framework of the post-Roman Lusitania. The urban bishopric of Egitania -located in the so-called Paço dos Bispos-, features a significant and well-preserved sixth century episcopal complex enclosed by the late Roman walls, which is integrated of a range variety of buildings. From 2016, the aim of this research has been to conduct a multidisciplinary study of the townscape development by recording the archaeological data, and applying remote sensing technologies to the material evidence. The stratigraphic study of the walls has also made possible to identify the original plan of the episcopal structure from other constructive added periods, and the specific technical characteristics that were used. The goal of this work is also to understand the evolution of the power architecture (both civil and ecclesiastical), continuities and changes detected in the urban architectonical patterns of the ancient Lusitania. Finally, the purpose is to explain the cultural factor, that is, the social, economic and ideological nature of urban walls, churches, episcopia, palaces, etc., studying building techniques, materials and the different chronological stages. As Emerita Augusta, for instance, Egitania illustrates perfectly the interaction between the episcopal local power and the Visigoth Kingdom of Toledo through the main components of the townscape (walls and architecture of prestige), the on-going road network communication and the economic sources of the Egitanian bishopric that was based in the exploitation of the natural resources of its territory.

\section{KEYWORDS}

LUSITANIA, IDANHA-A-VELHA, LATE ANTIQUITY, CHRISTIANIZATION, ARCHITECTURE, TOWNSCAPE

\section{De municipium romano a sede episcopal tardoantigua}

La freguesia de Idanha-a-Velha es una de las aldeas históricas de la comarca de Castelo Branco (Beira Baixa, Portugal) localizada en el occidente peninsular (fig. 1). Asentada en la margen derecha del río Pônsul, afluente del Tajo, a una altitud máxima de $284 \mathrm{~m}$ en las tierras bajas de Monsanto, la aldea actual es la suma de la continuidad de edificios y espacios de poder de épocas anteriores, de la superposición de ocupaciones y de una topografía urbana en transformación que, a través de los distintos edificios construidos, han ido modelando un paisaje específico. El entramado de la localidad moderna y contemporánea ha fosilizado la topografía romana y medieval, y se conservan algunas de las construcciones urbanísticas históricas más importantes como la muralla y parte del episcopio tardoantiguo.

Integrada en la provincia romana más occidental del Imperio, Lusitania (conventus Emeritensis) (Alarcão, 1988), la ciuitas Igaeditanorum quedó configurada desde época augustea con un amplio territorio que abarcaba parte de la cuenca hidrográfica del Tajo y gozó de una situación geográfica privilegiada en plena vía de comunicación entre Emerita Augusta y Bracara Augusta (Mantas, 1988b: 415-439; Sá, 2007: 61 n. ${ }^{\circ}$ 54). El origen de la ciudad romana, que nunca alcanzó el rango de colonia, pudiera vincularse con la existencia de caminos de trashumancia entre la Serra da Estrela y las tierras bajas al este del Beira (Cristovão, 2005: 191), pero también con la excelente comunicación por vía fluvial y terrestre y la presencia en el territorio de áreas mineras de naturaleza aurífera, como la Presa/Covão do Urso, Monfortinho y Rosmaninhal (González, 2008: 245), recurso que 
Figura 1. Localización de las principales ciudades lusitanas citadas en el texto (@ autora).

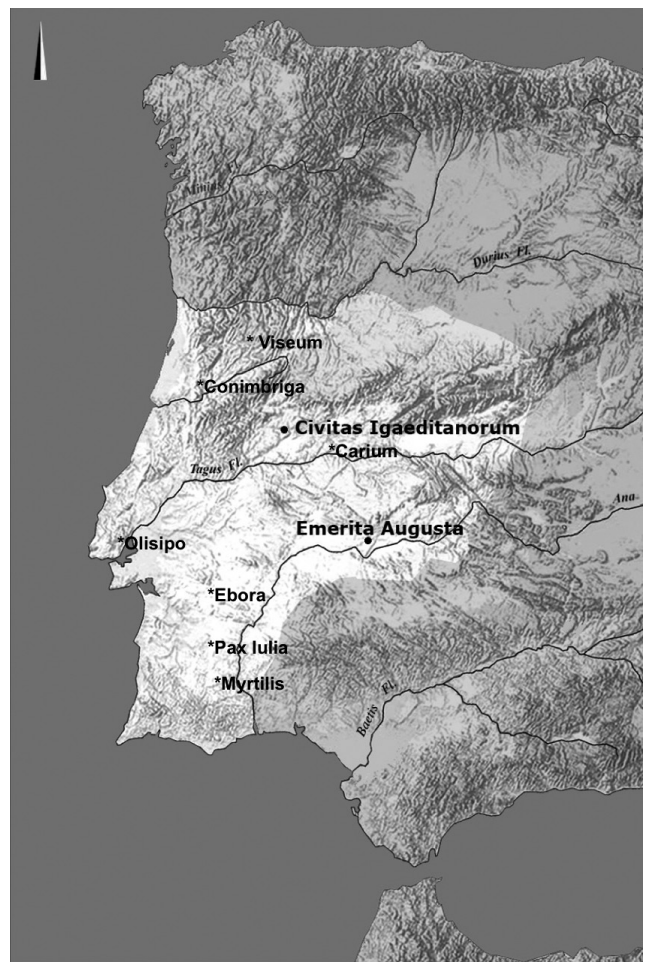

muy pronto sería fuente de riqueza para algunas de las familias locales como los Cantii (Carvalho, 2007: 103).

La superioridad de la ciudad y de sus élites frente a otras ciudades lusitanas, también puesta en evidencia por la inscripción que conmemora la participación de los Igaeditanii en la financiación del puente de Alcántara sobre el Tajo (re)construido entre el 104 y 106 (Pizzo, 2016: 14), para hacer pasar la vía que unía Norba y Conimbriga, ${ }^{\text {f }}$ fue recuperada por la sede episcopal creada en el siglo vi. No hay testimonios suficientes para conocer el devenir de la ciudad en el lapsus temporal transcurrido entre el siglo IV y vi, pero la arqueología revela una mínima ocupación o frecuentación del lugar y una transformación de la topografía urbana a través del expolio de los edificios romanos, y la aparición de las primeras estructuras cristianas.

La investigación ha discutido el momento exacto de creación de la sede episcopal, puesto que algunos autores la han relacionado con el rey suevo Teodomiro, ya desde el I

1. En la placa monumental del puente de Alcántara (CIL, II, 760) se alude a la participación de los municipios estipendiarios de la Lusitania que contribuyeron a la obra del puente, entre ellos los igaeditanos (Bonnaud, 2001: 5-35). El orden de aparición de cada uno de ellos se rige en función de su posición a lo largo de la vía de comunicación hacia Emerita Augusta. 
Concilio de Braga de 561 (Almeida, 1956: 39), la conversión al catolicismo del monarca y con la necesidad de crear nuevos obispados para mejorar la administración del territorio existente entre Viseo y Coria (Real, 2000: 28). Sin embargo, aparece citada explícitamente por primera vez con el nombre de Egitania en el concilio de Lugo de 569, presidido por Martín de Dumio, siendo Adorius el primer obispo egitano conocido (Vives, 1963).

La nueva diócesis del siglo vi mantuvo indivisible la extensión del territorio heredado de época altoimperial, limitando al norte con las sedes episcopales de Lamego y Viseo, al sur con la de Évora, al oeste con Coimbra y Lisboa y, al este, con los obispados de Salamanca y Coria. Es decir, a grandes rasgos el límite nororiental es Salama (Xálama) y el oriental, Mauriella (Moraleja) (Carvalho, 2007: 125). Egitania era el obispado de mayor extensión en Lusitania junto al emeritense, que transitoriamente formó parte del reino suevo, hasta que el obispo metropolitano Oroncio pudo reintegrarla en el grupo de diócesis lusitanas, según las actas del X Concilio de Toledo (656). De ahí también su inclusión en el Parrochiale Suevum a finales del siglo vI, un documento que atribuye cinco parroquias rurales a la jurisdicción eclesiástica de Egitania (Díaz, 2003: 138) y que pudo traducirse en una ampliación de su capacidad jurídica en estas fechas, al incorporar nuevos asentamientos o parroquias vecinas (Real, 2000: 25). La sede episcopal debió atravesar momentos de crisis y debilidad en el control de sus territorios tras la restitución de las fronteras de la Lusitania septentrional con el reino suevo. Una referencia significativa sobre el conflicto se trató en el Concilio de Mérida de 666, donde el obispo Selva reclamó la devolución de parte de unos territorios de su diócesis que habían pasado a la sede salmanticense (Vives, 1963: 330). Los hallazgos numismáticos y la presencia de una ceca local que acuña mone-

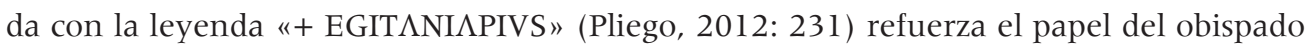
egitano y el poder que ostentaban las élites eclesiásticas en la recaudación fiscal a través de la red parroquial.

Una aproximación al estudio de las estructuras de poder en la Antigüedad tardía —identificación, evolución y difusión-, así como el análisis de los modelos arquitectónicos y las técnicas constructivas, morfología y funcionalidad en la ciuitas Igaeditanorum constituye la motivación principal de este trabajo. En la que fuera ciudad de los igaeditani hemos buscado la posible implantación de los modelos urbanísticos y arquitectónicos irradiados por los centros de poder visigodos más influyentes como la sede metropolitana emeritense.

\section{Nuevos proyectos, actuaciones y recursos metodológicos}

Los recientes estudios que han afrontado la topografía y las construcciones tardoantiguas en Idanha-a-Velha deben enmarcarse en el conjunto de avances logrados en las últimas décadas con relación al conocimiento arqueológico de la ciudad cristiana (Gurt e Hidalgo, 2005: 73-93) y los edificios eclesiásticos que la caracterizan (Sánchez, 2014). La antigua ciuitas Igaeditanorum experimentó a partir del siglo IV varios procesos 


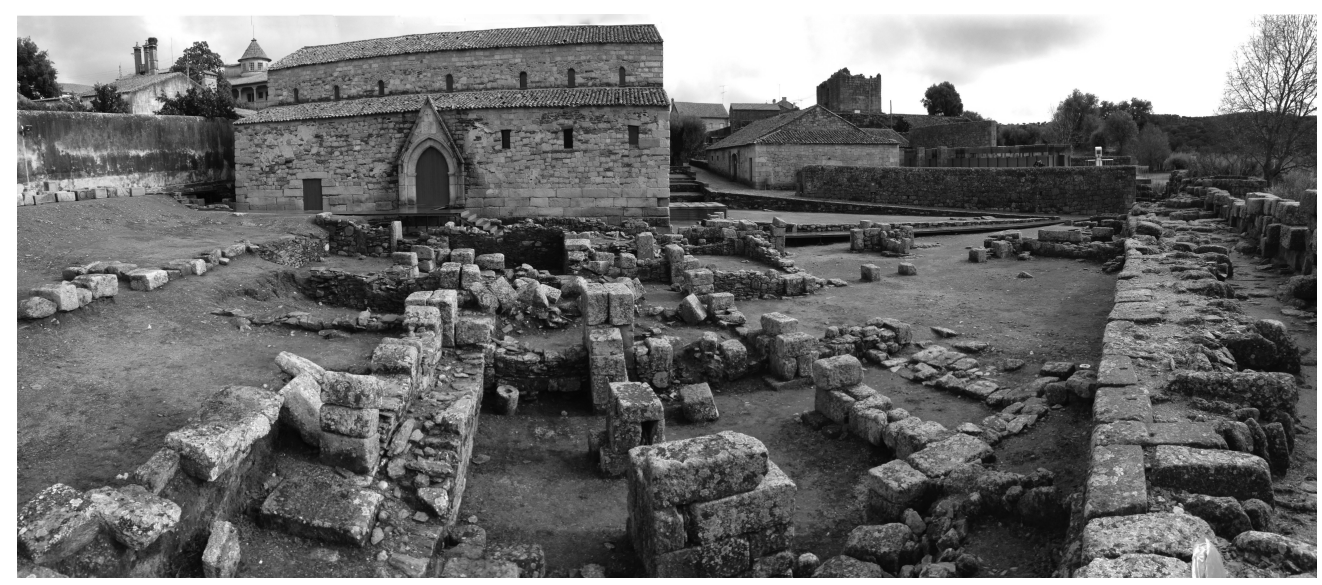

Figura 2. Vista del Paço dos Bispos en Idanha-a-Velha desde la muralla. En primer plano, estructuras del episcopium tardoantiguo; al fondo, la Sé-catedral (C) autora).

de transformación, continuidad y ruptura que modificaron su paisaje urbano, siendo comunes a los cambios producidos en otras ciudades hispanas y del mediterráneo occidental (Diarte y Christie, 2018). Sin embargo, los cambios que afectaron la fisonomía arquitectónica de la ciudad egitana en la Antigüedad tardía se caracterizaron, al mismo tiempo, por una serie de particularidades locales específicas, condicionadas por su emplazamiento geográfico, la geología del terreno, el clima y el desencadenamiento de varios episodios sísmicos.

En el sector denominado Paço dos Bispos se concentran —anexas a la muralla — las principales estructuras analizadas de este período. Su interpretación ha sido cuestionada por otros investigadores, que han apuntado la falta de testimonios para la datación e identificación de los muros visibles con un hipotético palacio episcopal del siglo vi, según la primera propuesta emitida por Fernando de Almeida (1966: 409), quien fuera el principal excavador del yacimiento durante la segunda mitad del siglo xx (Salvado, 1983; Baptista, 1998: 35). Entre la comunidad científica posterior a Almeida ha habido una significativa controversia en torno a los edificios tardoantiguos de Egitania, sometiéndose a discusión desde cuándo y por qué se construyó la muralla (Cristovão, 2002), sus técnicas constructivas (Caballero, 2006: 270) y la funcionalidad del edificio anterior a la Sé-catedral (Torres, 1992: 172), la identificación de la iglesia episcopal (Fernandes, 2005: 293-310) y hasta la misma definición territorial del obispado egitano (Cordero, 2018: 117).

La situación 'caótica' y de abandono que presentaba este conjunto hasta fechas muy recientes, así como la no publicación de las memorias de excavación, ha dificultado tanto la lectura arqueológica de los edificios y la comprensión de la evolución catastral del espacio urbano donde se localiza el conjunto de estructuras adscritas al grupo episcopal, como la elaboración de nuevos planteamientos interpretativos (fig. 2); 
ahí reside precisamente el origen primigenio y el reto de nuestro proyecto (Sánchez y Morín, 2017).

En este estado de la cuestión, el proyecto IdaVe ha buscado revitalizar la investigación de la ciudad en épocas tardoantigua y altomedieval, sin olvidar su pasado como municipium romano, gracias a la constitución de un equipo interdisciplinario, pero también a la colaboración mantenida con otros proyectos de investigación afines y paralelos centrados en la Lusitania romana (Pizzo et al., 2017).

Para abordar en toda su complejidad el estudio arqueológico de las transformaciones posteriores a la ciudad romana y los paisajes culturales que caracterizaron cada una de las ocupaciones, hemos elaborado en los últimos años una documentación meticulosa de las estructuras excavadas por Almeida. Se ha utilizado una metodología diversificada y escasamente invasiva, limitando al mínimo las excavaciones. La investigación ha sido innovadora en cierta manera, por la integración de una amplia variedad metodológica, en la que sobresalen la arqueosismología y el análisis de morteros con microscopía óptica, que nos permite dotar de coherencia los datos obtenidos en intervenciones precedentes, así como a nuestras propias actuaciones. Entre los recursos más empleados se encuentran las tecnologías propias de la teledetección aplicadas a la arqueología, porque facilitan la lectura y el registro gráfico exhaustivo de los datos de campo, al tiempo que nos han permitido generar con mayor rapidez planimetrías detalladas, secciones y alzados de los edificios. Las ortofotografías correspondientes al levantamiento topográfico del conjunto eclesiástico tardoantiguo, la muralla bajoimperial y la torre emiral sobre el templo del siglo I dC se han obtenido con la utilización combinada de varios sistemas de tratamiento de imagen (láser escáner 3D terrestre, dron y GPS) y han servido para construir un modelo digital tridimensional (fig. 3). Todo ello se completó con una prospección del territorio inmediato extramuros y la creación de un SIG del yacimiento. En suma, se han realizado trabajos arqueológicos no destructivos de fotogrametría, así como pequeñas campañas de excavación, con la finalidad de confirmar hipótesis previas, cronologías y obtener nuevas muestras para analíticas - morteros, pólenes, antracología, carpología, etc.- (Sánchez y Morín, 2015: 398-428).

Con el dron se ha obtenido una documentación fotográfica vertical de todos los tramos de la muralla, la Sé-catedral, el criptopórtico de la plaza del templo y de la torre medieval elevada sobre su podium. La ortofotografía de las estructuras en el Paço dos Bispos nos ha permitido diferenciar distintos momentos constructivos; es decir, desenmascarar las fases originales de la posible 'fábrica' episcopal de los añadidos y reformas posteriores, e identificar la secuencia constructiva-destructiva-constructiva del conjunto, así como definir las características técnicas y los materiales empleados en su arquitectura.

Para determinar si existía una relación entre las diferentes estructuras situadas en el interior de la Sé-catedral e inmediatamente al exterior, en la fachada norte, susceptibles de pertenecer al conjunto cristiano tardoantiguo, se ha realizado un estudio específico de morteros con un doble objetivo: por un lado, establecer una correlación entre las fábricas 

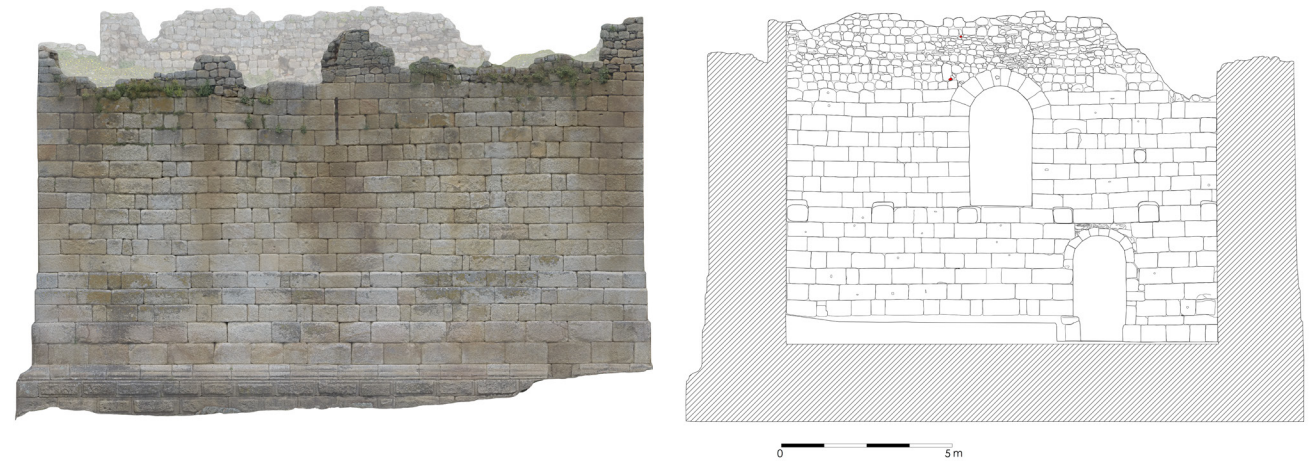

Figura 3. Fotogrametría terrestre de la torre medieval sobre podium del templo romano de la ciuitas Igaeditanorum. Izq.: Ortoimagen de la fachada sur tomada con dron. Dcha.: Alzado del lienzo interior septentrional dibujado a partir de ortofotografía vertical (@ Proyecto IdaVe).

y la cronología obtenida por metodología arqueológica y, por otro lado, obtener datos alternativos acerca de la manufactura de este material para generar posibles patrones de fabricación (Guerra, 2015). La metodología empleada ha sido una caracterización macroscópica completa y microscópica óptica de polarización, estableciendo la granulometría de los áridos, así como la caracterización mineral de algunos de los morteros más significativos (Hughes y Callebaut, 2000).

Por último, la principal novedad de este trabajo son las evidencias arqueosismológicas detectadas en la aldea, sobre todo en las estructuras antiguas del Paço dos Bispos, la Sé-catedral y la muralla (Hinzen et al., 201 1; Giner et al., 2011, 2012 y 2013; Korjenkov y Mazor, 2013; Rodríguez-Pascua, 2012 y 2013b). Se ha iniciado un estudio específico de la geomorfología local y del impacto que tuvieron los terremotos históricos en los edificios romanos y la fábrica episcopal tardoantigua. ${ }^{2}$ Se han inventariado hasta el momento diez conjuntos diferentes de efectos arqueológicos de terremotos (EAEs o earthquake archaeological effects), ocho como efectos cosísmicos, generados por deformación transitoria del sustrato (muros basculados, muros plegados, fracturas penetrativas en bloques de sillería, fracturas conjugadas a $45^{\circ}$, caídas orientadas, desplazamientos de bloques de sillería, claves de arco desplazadas y esquinas fracturadas) y dos, como efectos postsísmicos o indirectos (reparación de construcciones y elementos anómalos de reciclado). No había constancia en la zona de terremotos instrumentales y/o históricos relevantes anteriores al de Lisboa de 1755, por lo cual, los datos y los EAEs documentados indican que este lugar estuvo afectado de manera significativa y reiterada por una actividad sísmica en campo cercano y en campo lejano.

2. El estudio arqueosismológico en Idanha-a-Velha se realiza conjuntamente con el Instituto Geominero de Madrid, Universidad Autónoma de Madrid y Universidad de Salamanca, en el marco más amplio de la investigación sobre terremotos históricos en el Mediterráneo occidental (Rodríguez-Pascua et al., 2019: 190). 


\section{Arquitectura de poder y paisaje urbano}

La investigación arqueológica sobre las arquitecturas vinculadas a las élites en la Antigüedad tardía se ha consolidado como imprescindible para reconstruir la vida urbana de las ciudades de esta época y la imagen de los nuevos paisajes de poder generados en ellas. De sobra es conocido que la arquitectura siempre se ha utilizado para legitimar el poder de unas élites, y que ha estado instrumentalizada como canal de transmisión de su estatus e ideología. La arqueología de la arquitectura ofrece el enfoque interdisciplinario idóneo para comprender las sociedades históricas, y ha afrontado el conocimiento de los procesos constructivos desde nuevas y diversas perspectivas (económicas y sociales) que integran el paisaje y los condicionantes geográficos/locales, trascendiendo, por tanto, la forma física del edificio mismo. El estudio estratigráfico de las fábricas, además de evidenciar una manera particular de construir, refleja la idiosincrasia y el potencial económico de sus promotores, así como la capacidad y la habilidad de sus constructores en una u otra técnica (Quirós y Fernández, 2012: 43). No es lo mismo la cantería que la mampostería ni la reutilización de materiales, ni tampoco la tecnología empleada en el sistema de cubiertas. Un buen ejemplo de evolución tecnológica en las formas de construcción se encuentra en las bóvedas de las iglesias del grupo episcopal de Terrassa (García, Moro y Tuset, 2009). La discriminación en el uso de un tipo u otro de material, o el reciclaje, es otro de los aspectos importantes en estos estudios, que concluyen igualmente en etiquetar el proceso constructivo tardoantiguo heterogéneo según el contexto social y el entorno (Utrero, 2017: 200). En este sentido, en la proyección y finalmente construcción y fundación de los nuevos edificios y centros de poder, estuvieron implícitas cuestiones relacionadas tanto con los agentes sociales y la intencionalidad de sus fundadores (reyes, aristócratas, obispos, milites, etc.), como económicas, técnicas, funcionales y topográficas. La arquitectura eclesiástica es el mejor exponente para identificar la presencia de la monarquía, del clero y de las oligarquías en la ciudad y en el territorio; por tanto, es indisociable y producto de la realidad socioeconómica, religiosa y política del momento.

Pero ¿qué formas para qué función adoptaron las nuevas arquitecturas tardoantiguas en las antiguas ciudades romanas de Lusitania? ¿Qué modelos arquitectónicos seleccionaron las élites como vehículo de prestigio o estatus? Una primera encuesta sobre estas cuestiones concluye de nuevo que no existe ningún patrón, modelo ni estereotipo estándar que defina los edificios urbanos en estudio. Hay que admitir que los edificios identificados - principalmente de carácter eclesiástico- que aportan información suficiente para realizar este tipo de estudio son mínimos, y se corresponden con los siguientes: en Egitania: piscina bautismal 1; piscina bautismal 2 (episcopal), posible horreum, iglesia cruciforme, posible domus episcopalis; en Emerita Augusta: basílica martirial de Santa Eulalia, iglesia de San Pedro, xenodochium, edificio público y civil del foro; en Myrtilis: edificio bautismal 1 con deambulatorio, edificio bautismal 2, conjunto tardoantiguo del Castelo, y basílica de Rossio do Carmo. Las piscinas bautismales documentadas en estas ciudades responden a distintos esquemas (planta cuadrada, cruciforme y octogonal) e influencias (peninsulares, nortea- 
fricanas y del norte de Italia) (Beltrán, 2017: 101); las iglesias emplean bien, una planta basilical tradicional con ábside semicircular/rectangular exento, doble ábside contrapuesto, o una planta cruciforme inscrita siguiendo modelos comunes en todo el Mediterráneo (Ripoll, 2009: 230); los edificios residenciales de prestigio mantienen una planta rectangular con contrafuertes externos, división interna tripartita y doble altura (Polci, 2003: 89), mientras que el modelo del xenodochium emeritense es hasta el momento excepcional en la arquitectura tardoantigua lusitana y del resto de la Península (Mateos, 2003: 90).

\section{Discusión}

Si bien la Lusitania romana se articulaba por una nutrida red de ciudades (coloniae y municipia), monumentalizadas, amuralladas y con excelentes comunicaciones terrestres entre ellas, no todos los centros urbanos sobrevivieron a los cambios acaecidos en la Antigüedad tardía, y no en todos los que tuvieron cierta continuidad se puede estudiar la evolución de los modelos arquitectónicos urbanos. Por eso este trabajo ha priorizado una serie de casos de estudio representativos del fenómeno, encabezados por la ciuitas Igaeditanorum, sobre la base del nivel de documentación arqueológica disponible. Emerita Augusta, Myrtilis, Ebora y Conimbriga son otras ciudades ilustrativas en las que se identifica una serie de rasgos de transformación comunes relativos a su topografía e imagen urbana: a) pervivencia y reforma de las murallas; b) alteración del viario; c) desaparición de los complejos monumentales públicos y de las grades domus aristocráticas; d) desuso de las infraestructuras de saneamiento, red hidráulica y aparición de nuevos sistemas de almacenamiento de agua; e) nueva arquitectura de poder, pública y civil; f) nuevos modelos de hábitat, y g) aparición de nuevos espacios y arquitecturas ligadas al cristianismo. De entre estos cambios, solamente se han seleccionado para este trabajo aquellas manifestaciones que, constatadas en la ciuitas Igaeditanorum, pueden ser analizadas también en los centros urbanos citados anteriormente.

\subsection{Las murallas}

Las murallas constituyen una de las principales estructuras que caracterizaron las antiguas ciudades hispanas, si bien muchas de ellas se construyeron durante la Antigüedad tardía, redibujando así los paisajes urbanos, y transformando paralelamente el concepto de ciudad y su percepción por los contemporáneos. En este nuevo paisaje en construcción es también importante el impacto de los spolia, tanto por lo que en términos urbanísticos representó el desmantelamiento de los edificios altoimperiales previos, como por su utilización en la construcción de nuevos referentes arquitectónicos como los recintos amurallados (Utrero y Sastre de Diego, 2012: 311$)$. Las técnicas constructivas, los materiales, las fases crono- 
lógicas y la estructura final resultante son algunos de los aspectos más estudiados por la investigación (Maciel y Campos, 1994: 75). En el caso de los recintos amurallados de las ciudades de Lusitania, hemos realizado una fotogrametría completa de la muralla de la ciuitas Igaeditanorum, a partir de las imágenes captadas por un dron, con la idea de abordar un futuro análisis comparativo de técnicas constructivas con las murallas de Caurum, Conimbriga y Emerita Augusta, y establecer posibles diferencias y similitudes de los procesos constructivos que pudieron caracterizarlas, proponiendo, además, un marco cronológico del fenómeno.

El fenómeno de construcción de murallas bajoimperiales en el noroeste peninsular es complejo y heterogéneo en cuanto a su diversidad tipológica, contextos y amplia cronología, que suele fijarse entre finales del siglo III y primera mitad del siglo IV. Al tratarse de ciudades localizadas junto a la vía entre Emerita Augusta y Asturica Augusta - principal corredor de comunicación terrestre-, la proliferación de fortificaciones se ha relacionado con motivaciones militares y territoriales, con la explotación minera, pero también con el control fiscal y la captación de la annona, su circulación y distribución en épocas tetrárquica y constantiniana. No obstante, investigadores como K. Bowes han señalado que el limitado conocimiento de las vías annorarias en el nordeste de Lusitania, la falta de evidencia arqueológica y la existencia de otras vías más eficaces como la fluvial, siguen sin confirmar este argumento como causa única del fenómeno (Bowes, 2013: 212). Por ello, no debiera descartarse una interpretación conciliadora: recintos fortificados que cumplieran la función de definir y dignificar espacialmente centros de poder surgidos en el siglo iv como cabeza de amplios territorios, como Aeminium, Aquae Flaviae, Caurium, Ebora, Ossonuba, etc., a los que se podría sumar la ciuitas Igaeditanorum, sin prejuicio de contribuir también a proteger y encauzar una recaudación tributaria comarcal (no se sabe cuál) al amparo de las ciudades fortificadas. Esta función podría ser similar a la que cumplirán posteriormente aquellos castra tardoantiguos de la periferia occidental en el valle del Duero, donde se han recuperado pizarras numerales que contabilizan los pagos en especies (Gutiérrez, 2014: 199).

Aunque por el momento no se ha podido confirmar la construcción de una muralla en época altoimperial, se estima que la ciuitas Igaeditanorum tendría una extensión urbana aproximada de unas 10 ha, articulada en función de dos ejes viarios principales, uno con orientación norte-sur que se proyectaría a lo largo de unos $550 \mathrm{~m}$ de longitud en las actuales rúas do Castelo y de Guimãres, y el otro con desarrollo este-oeste con unos 300 m, fosilizado en la rúa da Sé y largo da Igreja (Cristovão, 2005: 194). El límite urbano septentrional parece coincidir con el posterior trazado de la muralla bajoimperial, habida cuenta de la presencia de una zona funeraria pocos metros más al norte del recinto tardío (Cristovão, 2005: 192).

La investigación ha propuesto fijar cronológicamente la construcción ex novo de la muralla de la ciuitas Igaeditanorum, como la de su vecina Caurium (Coria), entre finales del siglo III e inicios del IV dC (Gil, 1999: 380). Se trata de un recinto fortificado con $745 \mathrm{~m}$ de perímetro rodeando un espacio intramuros de unas 5 ha. Su construcción representó una reducción de la ocupación urbana altoimperial, como así parece confirmarse en su lienzo 


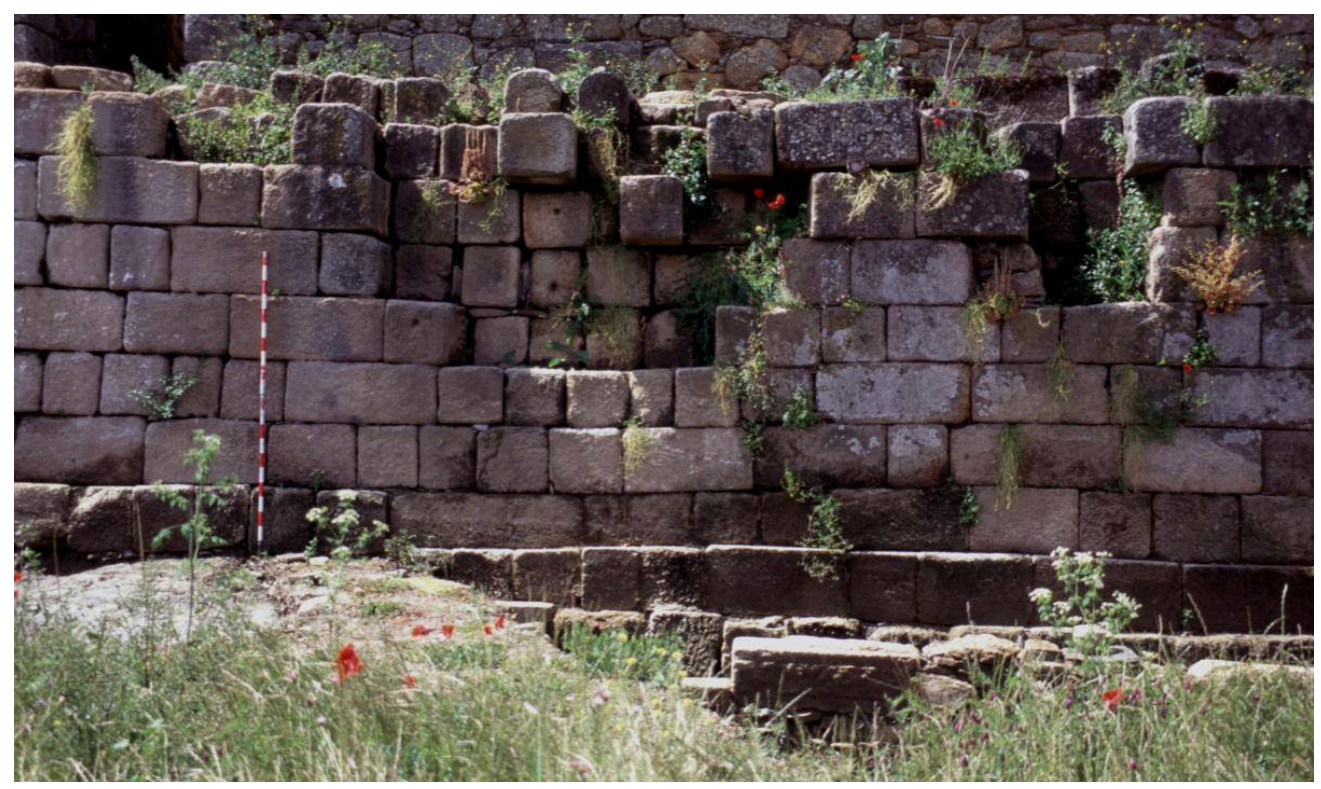

Figura 4. Lienzo septentrional de la muralla de la ciuitas Igaeditanorum en 1987 antes de la restauración (C cortesía de A. Malalana).

meridional cimentado directamente sobre una domus del siglo II dC. Del nuevo recinto amurallado sobresale la Puerta Norte o de Monsanto que, como sucede en los accesos de otras murallas hispanas coetáneas (Rodríguez y Rodà, 2007), está flanqueada por dos torres de planta semicircular. En el tramo suroccidental se abre una poterna junto a la torre rectangular que flanquea la Puerta Sur o del Pônsul, ya que en época romana salía desde este lugar la calzada que conducía al río del mismo nombre, salvado por un puente sobre el que pasaba la vía entre Emerita Augusta y Bracara Augusta por Viseum (Alarcão, 1988: 101).

El recinto murario actual de Idanha-a-Velha es el resultado de las reformas y reconstrucciones realizadas a lo largo del tiempo y, finalmente, de la restauración acometida en la segunda mitad del siglo xx. La estructura original que cabría situar en la Antigüedad tardía está construida con bloques de sillería reutilizados y expoliados de edificios romanos, junto con abundante material constructivo y epigrafía altoimperial (fig. 4). Tras la publicación de J. Salvado (1983), el único estudio monográfico sobre la muralla de Idanha-a-Velha fue realizado por J. Cristóvão (2002); no obstante, en este trabajo no se alcanzan unas conclusiones cronológicas ni tipológicas satisfactorias, ni se aporta una explicación al uso masivo de material romano de expolio en su construcción.

El estado de conservación de la muralla es óptimo, sobre todo en los tramos septentrional y occidental, que se asientan en rocas metamórficas ordovícicas. Sin embargo, la zona occidental presenta algunas anomalías estructurales como desplazamientos en bloques de sillería, pliegues y trazado sinuoso del paramento, y la pérdida de alguna de 
las torres. Las deformaciones detectadas aquí, gracias al estudio arqueosísmico realizado, se han puesto en relación con el efecto producido por un terremoto histórico, que se documenta en otras zonas del recinto. El tramo oriental es el que presenta los efectos más llamativos de un episodio sísmico, como la pérdida del revestimiento externo, desplazamiento (superando el módulo del vector de $25 \mathrm{~cm}$ ) y pérdida de bloques de sillería, fracturas penetrativas asociadas a pliegues del paño de la muralla, y la deformación sinuosa de la línea de muralla.

Otros centros urbanos lusitanos, como Emerita Augusta — que ostenta la mayor extensión espacial, de entre 85 y 100 ha (Mateos, 2004: 27-39)— junto a Myrtilis, Olisipo, Pax Iulia y Salmantica, disponían de murallas desde el siglo I, que fueron normalmente reformadas en momentos posteriores: en la capital emeritense se realiza una reforma en el año 483 a instancias de Eurico, junto al puente y otros edificios públicos (Mateos, 2004: 38), en Viseum se constata la reconstrucción de una parte del recinto en el siglo III (Inês, 1999: 401); y en Conimbriga, el trazado de la muralla altoimperial fue modificado en época bajoimperial, reforma que incluyó el edificio del anfiteatro en el nuevo recorrido fortificado; al mismo tiempo, representó la anulación de algunas de las grandes domus urbanas que quedaron extramuros, como la Casa de los Surtidores y las construcciones situadas al sur de la vía de acceso a la ciudad, que fueron igualmente demolidas para construir la nueva muralla tardía (Maciel y Campos, 1994: 75).

\subsection{Edilicia civil, pública y privada}

Los edificios y espacios romanos documentados en Idanha-a-Velha corresponden al templo y algunas estructuras del foro (Carvalho, 2009: 117), además de unas termas privadas situadas al sur del centro monumental, parte del trazado del Decumanus maximus, y una necrópolis con sepulturas de incineración de los siglos I-II dC en la zona septentrional a las afueras del centro urbano, junto a la citada vía Emerita-Bracara (Almeida y Ferreira, 1957: 158; Côrte Real, 1996: 24; Gil, 1999: 380). Con la anulación de estructuras republicanas, el foro se elevó en el punto topográfico más alto de la ciudad sobre una plataforma rectangular —o criptopórtico — sustentada por potentes muros de sillería de granito con contrafuertes, cuyo lateral occidental se encuentra preservado hoy en el 'Quintal da Torre'. Lo más significativo es la construcción de un templo — de cronología augustea o flavia- de planta rectangular $(30 \mathrm{~m} \times 73 \mathrm{~m})$ y con un podium con sillares almohadillados bien unidos, que ocupan el centro de una plaza con porticus triplex de 6,60 m y 6,20 m de longitud. Se ha documentado también la cimentación de los pilares de granito y los cimientos de los muros que delimitaban los pórticos. La técnica constructiva del templo del recinto sacro es idéntica a la adoptada por otros templos en la Lusitania romana (p.e., en Évora y en el templo de Diana, en Mérida), pero también en la misma ciuitas Igaeditanorum se constata la existencia de otros edificios con el mismo sistema constructivo de sillares almohadillados bien unidos y con una moldura saliente en la base (Cristovão, 2005: 197). Se trata de una 

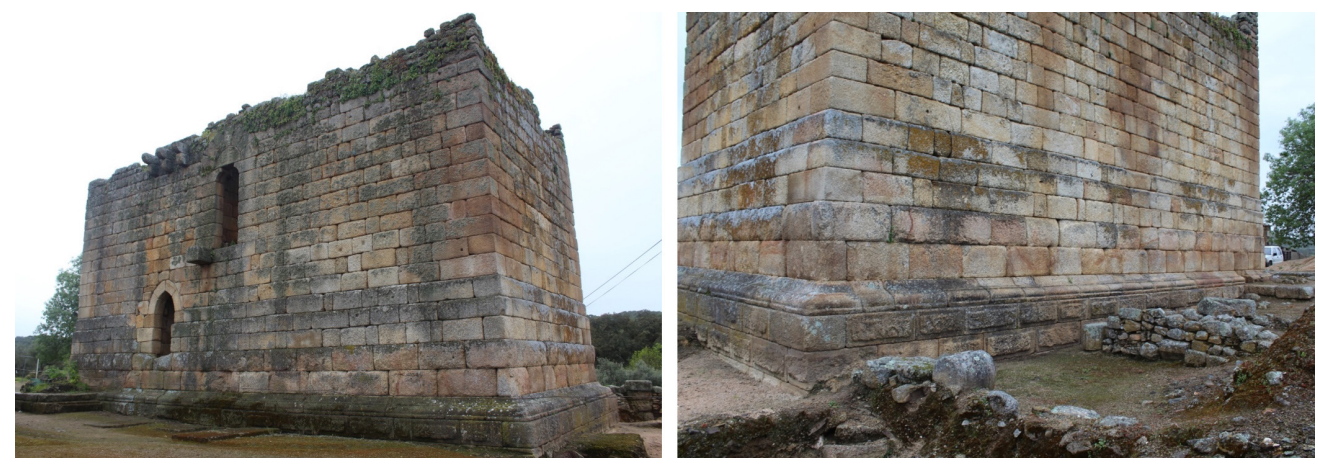

Figura 5. Muros de construcciones tardías adosados al templo romano que emplean mampostería y elementos reciclados (C autora).

estructura de gran entidad localizada junto al Decumanus maximus (rúa do Castelo) y de los muros perimetrales de la Sé-catedral que están perpetuando el trazado de un edificio de cronología altoimperial. El muro occidental de la iglesia apoya sobre una línea de sillares almohadillados cuya longitud es de unos $23 \mathrm{~m}$. En las primeras hiladas del ángulo suroccidental de la iglesia se aprecia una esquina que adopta una solución constructiva en cremallera, similar a la que presentan los templos lusitanos citados. El origen del conjunto arquitectónico y su desarrollo posterior han sido planteados por P. Carvalho (2009: 115-131), quien en 2008 dirigió unos sondeos arqueológicos en ese espacio público de la ciudad romana. Uno de los primeros síntomas de transformación de este espacio sacro se observa en los pórticos de la plaza que rodeaban el templo del siglo i, cuyos intercolumnios se cegaron en un momento incierto de época bajoimperial con muros de mampostería de sillarejo y lajas de pizarra (fig. 5). La compartimentación del espacio sugiere su posible privatización, quizá con una finalidad doméstica.

En otras ciudades de la Lusitania se produjeron unos procesos similares en cuanto a la transformación, reocupación, expolio y reconstrucción de la arquitectura romana pública (Diarte, 2012: 19). Los edificios sacros (templos), de espectáculos y el foro son los espacios de la ciudad clásica más significativos para este tipo de estudio en centros urbanos como Conimbriga, Ebora, Viseum, Pax Iulia y Emerita Augusta. Se dispone de un amplio conocimiento de esta última, capital de la Dioecesis Hispaniarum (Laterculus de Polemio Silvio) y sede del vicarius Hispaniarum (Arce, 2002: 16), donde se han documentado el abandono y el expolio del foro provincial, a partir del siglo $\mathrm{V}$, y la aparición de estructuras domésticas tardoantiguas (Mateos, 2004: 34), además de las transformaciones urbanas derivadas del fenómeno de cristianización del mundo funerario y de la topografía martirial (Mateos y Alba, 2000: 146). En ese sentido, es relevante señalar la construcción de un edificio público y civil fechado en el siglo v en el antiguo foro colonial. La edilicia empleada es una opera mixta de sillería de granito reutilizado, mampostería y lajas de pizarras como calzo, acorde con la arquitectura tardoantigua del resto de la ciudad (Ayerbe y Mateos, 2015: 186-190). No se ha constatado que hubiese un edificio de funcionalidad equivalente en Egitania, pero 
se trata de una arquitectura de poder y de representación que se conoce en otras zonas de la península ibérica, como Barcino, Falperra y Reccopolis, entre otras.

En conclusión, la dinámica común en las ciudades lusitanas es, por lo tanto, la continuidad del uso a través de la reocupación de los antiguos templos con diversas funcionalidades: doméstica, funeraria y/o sacra. También el foro suele permanecer como espacio central en la ciudad de la Antigüedad tardía, junto al que en ocasiones se presupone que se erigiera en grupo episcopal (Viseum, Ebora), pero sin que se pueda llegar a confirmar su emplazamiento definitivo.

\subsection{Arquitectura eclesiástica: grupo episcopal}

Las principales ciudades lusitanas tras la desaparición de la Dioecesis Hispaniarum fueron 15 centros urbanos que, excepto Mértola (fig. 6), alcanzaron el rango de sede episcopal: Caliabria, Caurum, Ciuitas Coilanorum (Lamego), Ciuitas Igaeditanorum, Ciuitas Interanniensium (Viseu), Conimbriga (Condeixa-a-Velha), Ebora, Augusta Emerita, Myrtilis, Obila (Ávila), Olissipo, Ossonoba (Estoi-Faro), Pax Iulia, Portum Cale (Oporto) y Salmantica.

Los nuevos obispados se distribuyeron en función de la red de ciudades con rango de colonia y municipium, y se concentraron especialmente en la franja septentrional de la

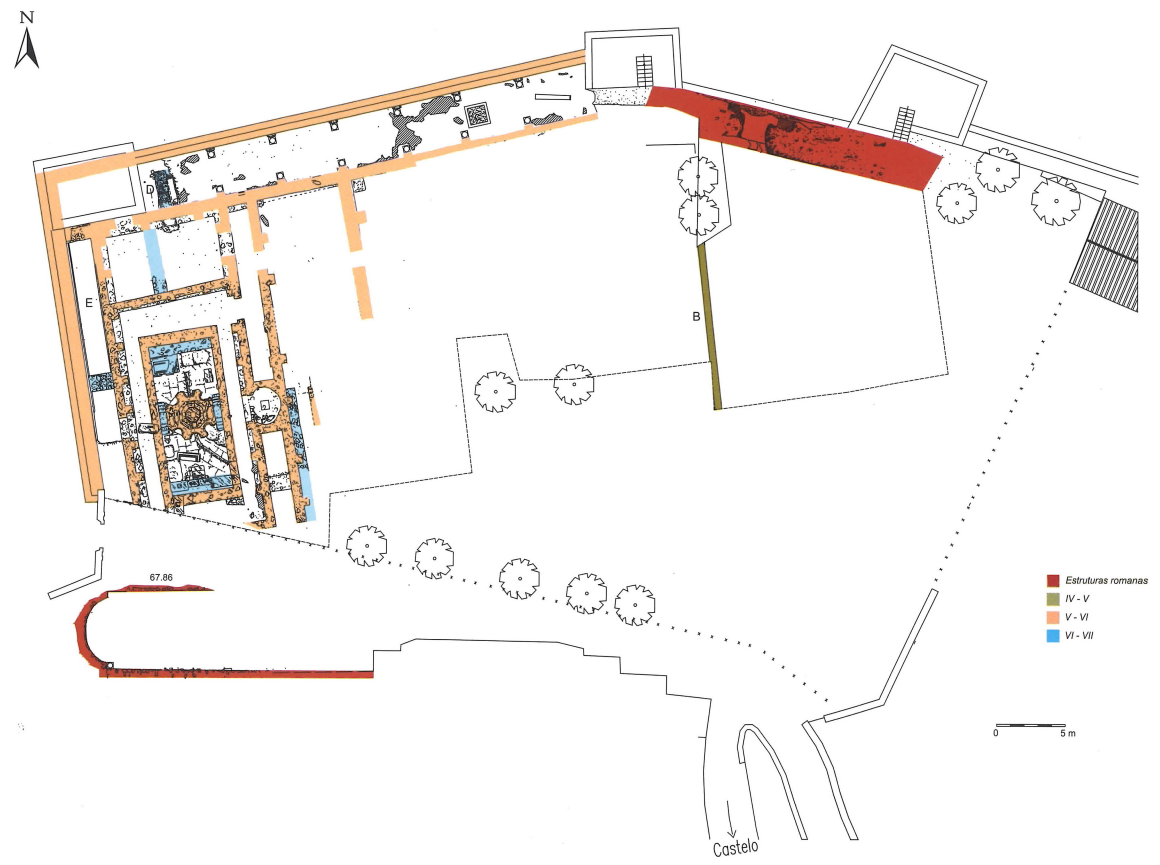

Figura 6. Conjunto cristiano localizado sobre el antiguo foro romano de Mértola (Lopes, 2004: 73, fig. 46). 
Figura 7. Construcciones cristianas en Emerita Augusta. Acceso a la cripta de los obispos en la basílica de Santa Eulalia (Sastre de Diego, 2017: 57).

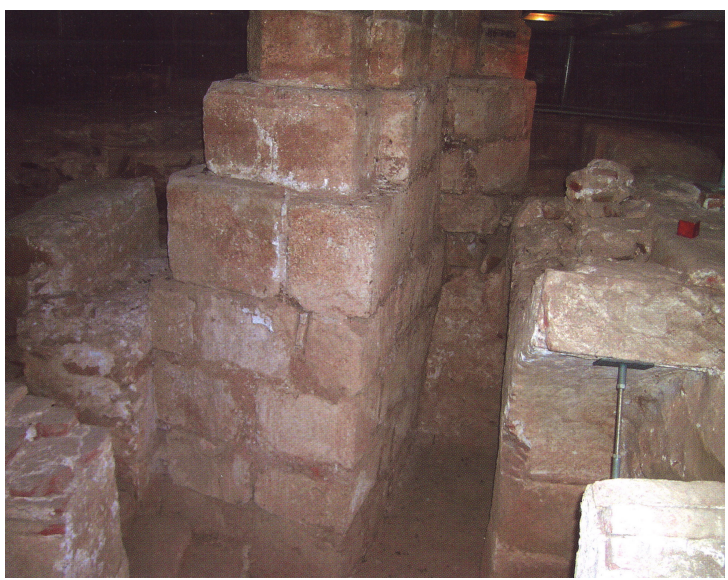

provincia, en la zona limítrofe con la Gallaecia. Las actas del concilio de Eliberri refieren la existencia de solo tres obispados en el siglo iv —Ebora, Emerita Augusta y Ossonoba- a los cuales, décadas más tarde, se sumará la sede episcopal de Abela. A mediados del siglo vi, sobre todo a partir del III Concilio de Toledo (589), se consolidó el mapa eclesiástico citado con la creación de nuevas sedes episcopales, algunas de las cuales, como Viseum, Lamecum y Egitania, están recogidas en el Parrochiale Suevum por lo que formaron parte de manera transitoria del reino suevo de Gallaecia. De las fundaciones episcopales más recientes, al menos dos correspondían a aglomeraciones secundarias o de entidad indeterminada (Caliabria y Caurium).

Si con estos mismos datos tuviéramos que plantear un reparto teórico de la administración diocesana de Lusitania, habría que suponer la existencia de obispados que controlaban un amplio territorio: sería la sede metropolitana de Emerita Augusta, seguida de la de Egitania, las que abarcarían una mayor extensión del territorio. De la Chronica de Sulpicio Severo se deduce que, a finales del siglo IV, el control del obispado emeritense era efectivamente uno de los más deseados por las distintas facciones cristianas de la provincia, toda vez que Emerita Augusta dejaba de ser la sede del vicarius Hispaniarum (Arce, 2003: 129). Llegado el siglo vi, la capital se había convertido ya en una de las sedes metropolitanas más prestigiosas de la Hispania visigoda e incluso llegó a rivalizar con la sede de Toledo. Como en otras ciudades hispanas importantes - Barcino, Hispalis, Valentia y Toletum, entre otras - sabemos de la presencia del obispo arriano Sunna en época de Leovigildo, que se apropió de algunas de las iglesias católicas. El poder episcopal al que nos referimos se manifiesta con claridad en el opúsculo anónimo dedicado a las vidas de los obispos de la ciudad (Vitas Sanctorum Patrum Emeretensium), entre los que destacaron los orientales Paulo y Fidel, y el godo Masona (Maya, 1992) (fig. 7). Las V.S.P.E. son al mismo tiempo uno de los principales testimonios escritos que se refieren a la iglesia episcopal (ecclesia senior, sancta Iherusalem o Santa María), al palacio episcopal reconstruido por el obispo Fidel y 


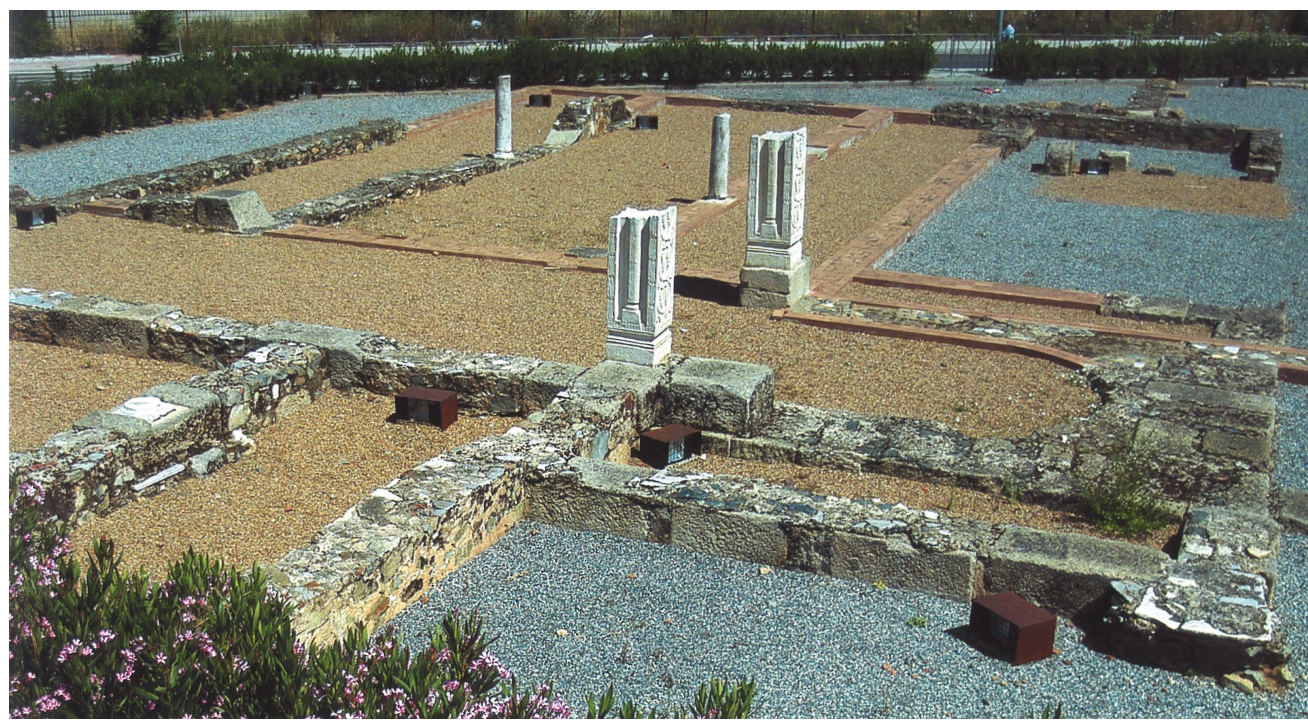

Figura 8. Construcciones cristianas en Emerita Augusta. Xenodochium (Sastre de Diego, 2017: 63).

a los monasterios establecidos en el entorno de la capital emeritense. En el mismo texto se citan otros edificios de culto intra y extramuros importantes, no siempre identificados arqueológicamente, pero que permiten reconstruir vagamente el paisaje y la topografía cristiana de la ciudad. La evidencia material refleja, a su vez, una profunda cristianización de la topografía urbana, en la que destaca el espacio martirial y religioso — que incluía un xenodochium - formado en torno al tumulus de la veneradísima santa Eulalia, una de las mártires hispanas más aclamadas por la comunidad cristiana local, cuya fama trascendió rápidamente el ámbito provincial (Ayerbe y Mateos, 2015: 188) (fig. 8).

Más allá de Mérida, aunque en las últimas décadas se ha alcanzado un conocimiento preciso de la transformación urbana de las ciudades romanas de Lusitania, lo cierto es que la evidencia material es bastante dispar, y apenas permite reconstruir el paisaje de la ciudad tardoantigua. Respecto a la cristianización, la investigación ha tratado de definirla a través de la arquitectura eclesiástica, las necrópolis y la articulación del territorio episcopal en torno a la ciudad. No en todos los obispados lusitanos se documentan construcciones adscritas cronológicamente al período en estudio, que hayan consentido estudiar la evolución de su urbanismo ni realizar un análisis detallado de los edificios, de sus paramentos, materiales y de las características técnicas empleadas; se carece incluso de testimonios arqueológicos fehacientes para identificar y conocer la estructura del complejo episcopal en estas ciudades. En ese sentido, salvo en localizaciones concretas como Emerita Augusta, Myrtilis y Egitania, resulta complicado identificar la funcionalidad y la tipología de los nuevos edificios urbanos cristianos y, consecuentemente, el establecimiento de patrones y/o modelos arquitectónicos constructivos por parte de la investigación está sujeto a la 

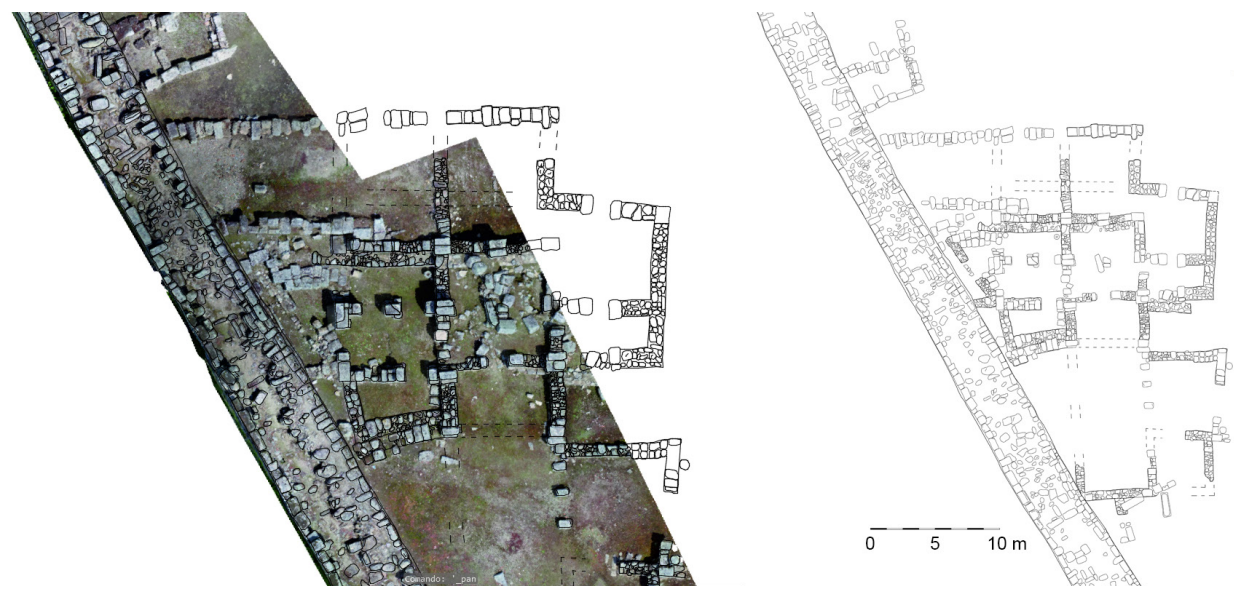

Figura 9. Paço dos Bispos, posible edificio de culto junto a la muralla. A: Fotogrametría aérea y planimetría. B: Planimetría completa a partir de la fotogrametría aérea (@ Proyecto IdaVe).

parcialidad de los datos arqueológicos disponibles. Myrtilis, por ejemplo, refleja la presencia de unas élites locales que dejaron constancia de su poder en el paisaje urbano a través de una arquitectura religiosa y funeraria relevantes (Lopes, 2017: 13-89). Fue una ciudad próspera por su emplazamiento en un cerro sobre el Guadiana, navegable hasta Mérida, y por ser el puerto fluvial de la sede episcopal de Pax Iulia. En la zona del Castelo se han localizado dos conjuntos bautismales monumentales, a escasos metros uno del otro; ambos se caracterizan por la presencia de piscinas bautismales de planta octogonal revestidas de mármoles expoliados, como en Egitania, y cuyos modelos arquitectónicos hay que buscar en los baptisterios del norte de Italia. Se desconoce el edificio de culto al que se adscribiría el complejo bautismal porticado del siglo v instalado en el foro (fig. 6). La piscina de planta octogonal, como la del grupo episcopal de Barcino, se inserta en un espacio rectangular (Lopes y Macias, 2005: 457). Especial mención merece la rica ornamentación de los mosaicos que pavimentan el pórtico de acceso al edificio bautismal.

La excepción a todo es, por tanto, Idanha-a-Velha, donde se ha documentado con certeza el único espacio episcopal conocido de la antigua Lusitania. El conjunto eclesiástico se localiza intramuros, junto al lienzo occidental de la muralla bajoimperial, en el cuadrante suroccidental de la ciudad, y a escasa distancia del templo del recinto sacro levantado en época augustea en la cota más alta del centro urbano. El episcopium se encontraría situado también al oeste del Cardo maximus, y ocuparía al menos una de las insulae de la malla urbana altoimperial, cuyo trazado no se ha documentado con certitud, pero se puede deducir a partir de la definición de los límites del perímetro de la plaza donde se ubica el templo y del antiguo viario romano preservado, en parte, en la topografía de la aldea actual (fig. 9). La posición y el desarrollo espacial del conjunto a lo largo de la Antigüedad tardía estuvieron igualmente condicionados por la muralla tardía y, posiblemente, por la presen- 


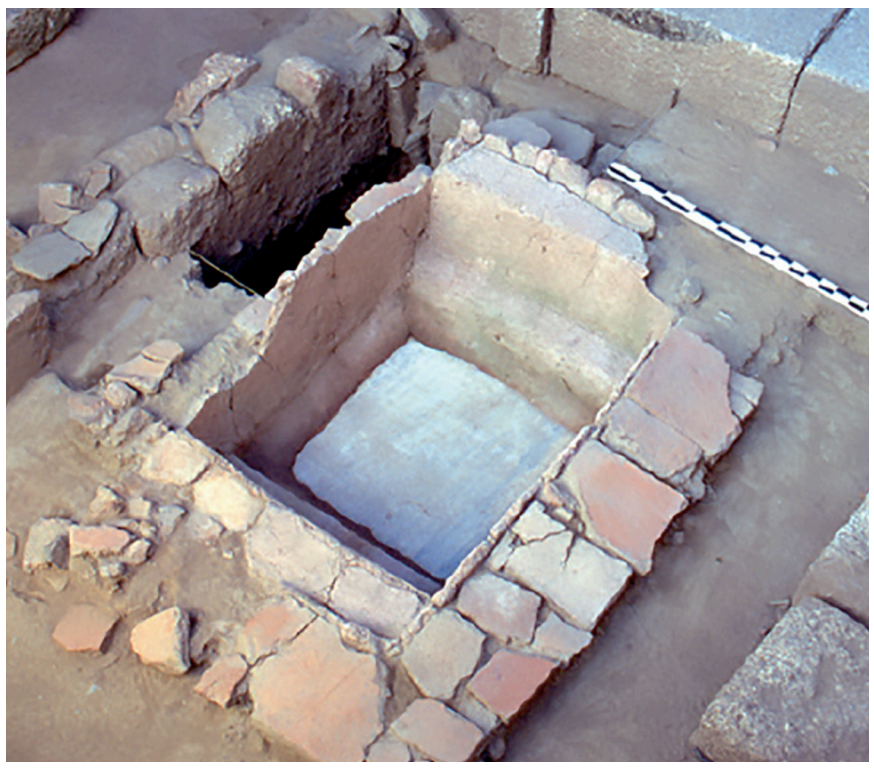

Figura 10. Primer baptisterio fechado hacia mediados del siglo v (@ cortesía de J. Cristovão).

cia en el lugar de un edificio de características constructivas, funcionalidad y cronología desconocidas, que quizá pudo determinar la ubicación del primer baptisterio constatado en la ciudad (fig. 10). Se trata de una piscina de planta cuadrangular, y escasa profundidad, revestida de placas de mármol reutilizadas; planteamos que se dispondría integrada en la parte occidental de una iglesia de nave única. Desconocemos si la existencia de aguas subterráneas en este lugar también influiría en su ubicación, de las que es testimonio el pozo al interior de la Sé-catedral, de cronología incierta, aunque el brocal está integrado en las primeras hileras de la pared occidental de la citada Sé, que podrían corresponder a una construcción de cronología tardoantigua, e incluso anterior dado el almohadillado de los sillares (Fernández, 2001: 37).

El complejo monumental episcopal estuvo constituido por varios edificios de los cuales se ha identificado, por un lado, una piscina bautismal de planta cruciforme localizada al sur de la Sé-catedral, en posición simétrica al baptisterio de planta cuadrangular constatado al exterior de la fachada septentrional (fig. 11). Esta segunda estructura bautismal formaría parte de la ecclesia episcopalis aún no identificada con claridad (fig. 12), pero que podría situarse inmediatamente al sur de la piscina, siguiendo una distribución similar a la adoptada por el conjunto cristiano de Torre de Palma (Maloney, 1995: 449-458). Ambas piscinas están construidas con sillarejos, ladrillos y forradas por placas reutilizadas de mármol de Estremoz, una variable técnica extraordinaria dada la presencia excepcional de mármol en la ciuitas Igaeditanorum (Sánchez y Morín, 2014: 69-71). Un reciente trabajo propone nuevas cronologías para ambas piscinas a partir de los resultados obtenidos por OSL (optically stimulated luminescence), radiocarbono y C14, del análisis de una serie de muestras de 
Figura 11. Segundo baptisterio adscrito a la fase episcopal hacia mediados del siglo vi (C) autora).
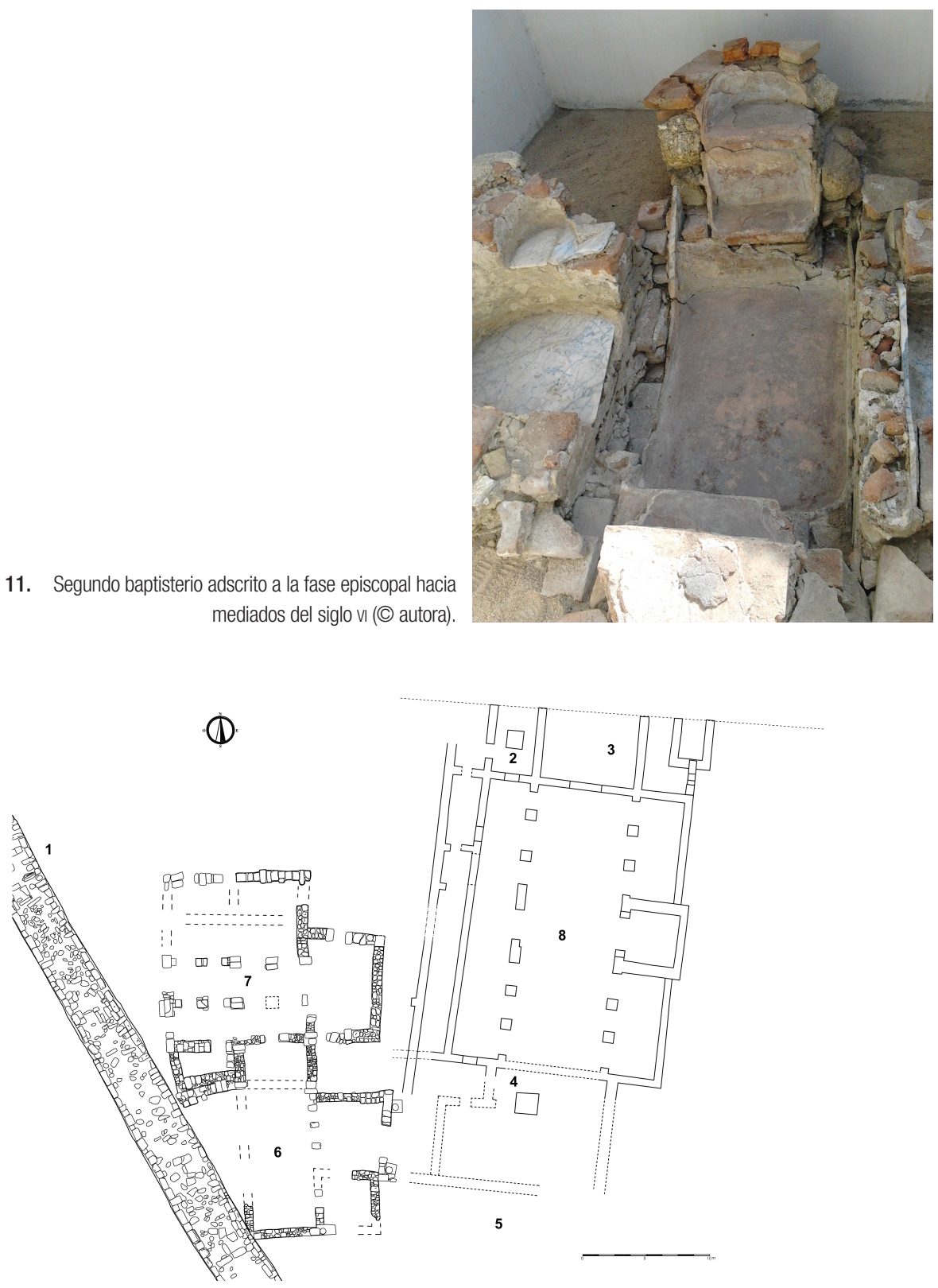

Figura 12. Paço dos Bispos. Propuesta de restitución topográfica de los espacios del grupo episcopal egitano de mediados del siglo v y del conjunto cristiano anterior: 1. Muralla; 2. Primer baptisterio; 3. Localización propuesta para la primera iglesia de la ciudad; 4. Baptisterio episcopal; 5. Localización propuesta para la ecclesia; 6. Posible horreum; 7. Edificio de culto; 8. Propuesta de ubicación de la domus episcopalis (C Proyecto IdaVe). 
material constructivo (ladrillo, opus signinum, mortero) y orgánicas (fauna y restos óseos humanos) (Fernández et al., 2019: 5697). Hasta ahora son los únicos datos empíricos que proporcionan unas dataciones para las estructuras cristianas no basadas en aspectos tipológicos. Sin embargo, no están ausentes de controversia dado la horquilla cronológica tan amplia que representan. También la interpretación final propuesta implica adelantar casi un siglo la construcción de ambos baptisterios; es decir, segunda mitad del siglo IV para la estructura norte y primera mitad del siglo v para la piscina sur, a un momento en el que supuestamente no se había creado el obispado egitano (Fernández et al., 2019: 5673). Por otro lado, en el Paço dos Bispos aparecieron también múltiples estructuras, pertenecientes muy probablemente a edificios distintos, pero que durante su excavación y la investigación posterior han sido interpretados unitariamente como la residencia del obispo (Almeida, 1966: 408-411). A continuación, ofrecemos su descripción morfológica y una nueva propuesta respecto a su funcionalidad y tipología.

En primer lugar, justo frente a la piscina cruciforme se ha identificado una gran sala rectangular cuya principal característica constructiva es la presencia de una hilera de pilastrones macizos interiores que la dividen en dos naves paralelas e iguales con una orientación norte-sur. Al no tratarse de pilares adosados en las esquinas, lo que indicaría su naturaleza tectónica para recibir los empujes de una planta superior, quizá su sentido sea fundamentalmente estructural. Se desconoce la funcionalidad de este edificio, pero su modelo arquitectónico y espacial encaja con la serie de aulas de dos naves con funciones de almacén que se constatan en varios conjuntos eclesiásticos y civiles de época tardoantigua en la península ibérica (Arce, 2011: 28 y 279), caso de Reccopolis (Arce, 2012: 28), El Tolmo de Minateda (Gutiérrez y Sarabia, 2013: 285), Barcino (Beltrán de Heredia, 2018: 115) y Santa Marta das Cortiças (Falperra) (Real, 2000: 27), entre otros.

La tipología estandarizada de edificio de planta rectangular con contrafuertes al exterior, y normalmente con una orientación norte-sur, destinada a almacén es muy frecuente en el territorio lusitano, caso de Los Términos (Monroy, Cáceres), Cañaveral (Cáceres) y Freiria (Lisboa) (Salido, 2013, 131-148). En otras partes de Europa, por ejemplo en Dichin (Danubio), Monte Barro (Italia), Lombren (Provenza) y en el castrum de Keszthely-Fenékpuszta (Hungría), se conocen también varios asentamientos fortificados de posición estratégica para la gestión de un territorio, que son controlados por unas élites, donde el surplus agrícola se almacenaba en los horrea documentados (Brogiolo, 2012: 12). Igualmente aparecen en Justiniana Prima (Caričin Grad, Serbia) y en Parentium (Poreč, Croacia), junto a sus respectivas ecclesiae episcopales. Tampoco podemos olvidar el carácter eminentemente fiscal de la ciudad en época visigoda como centro destinado al almacenaje y administración del grano (Arce, 2012: 29; Barroso et al., 2013: 257-308). La sede episcopal de Egitania respondería a este modelo de gestión territorial, dada la presencia de un grupo episcopal fortificado con probable horreum, a confirmar en futuras excavaciones y a través de nuevas analíticas de sedimentos.

Perpendicular a la estructura anterior, se documenta otra construcción que planteamos interpretar como un edificio de culto. En el ángulo suroccidental de la nave lateral sur 
Figura 13. Pilar de la arquería interna del edificio interpretado como iglesia en el Paço dos Bispos. La estructura tardoantigua se apoya en un muro de cantos rodados de cronología bajoimperial con orientación norte-sur (@ autora).

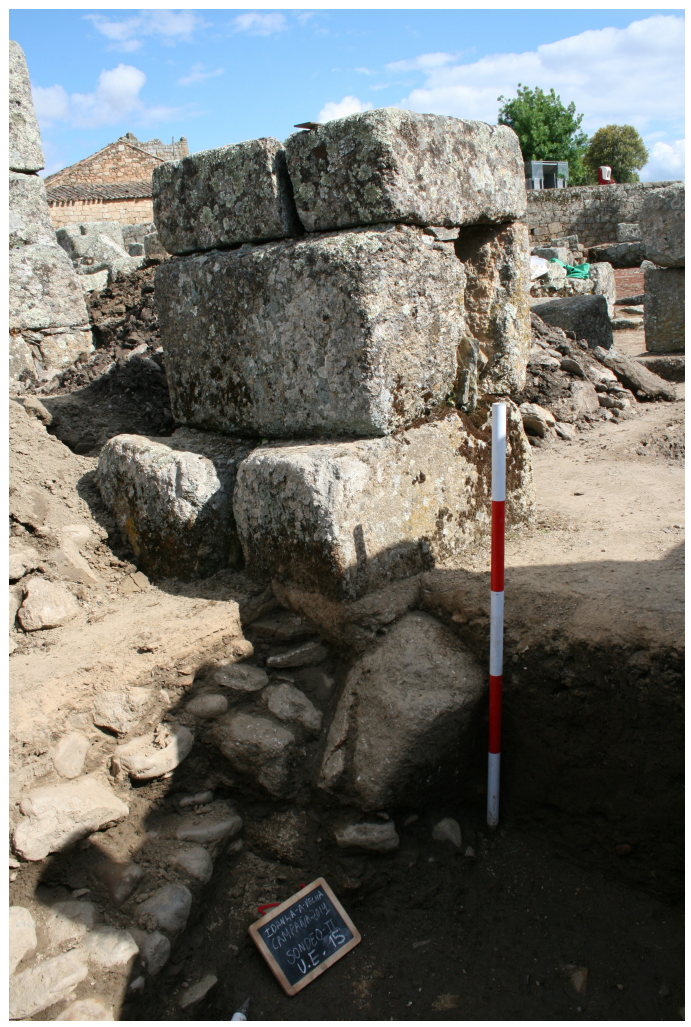

y en la zona occidental de la nave central de este edificio se abrieron dos sondeos en 2014 que confirmaron la secuencia cronológica de partida, según la cual los pilares cuadrangulares de sillares con la arquería y sus zapatas de cimentación pertenecen a un edificio de cronología tardoantigua o altomedieval (siglos VII-VIII). También se ha documentado un umbral de acceso a la nave central (Sondeo II/ U.E. 7), que emplea lajas de pizarra, y una base preparada con cantos rodados (1,25 $\mathrm{m}$ de potencia). La fachada occidental del edificio cristiano tendría una entrada que daría paso a la nave central, y existiría al menos otro acceso principal en la fachada septentrional (Sánchez y Morín, 2016: 416). Aunque se conserva el arranque de al menos tres arcos de herradura en su sector occidental (cegados en un momento posterior), la construcción se encuentra prácticamente arrasada y enmascarada por ocupaciones más modernas. La técnica edilicia del edificio se corresponde con el empleo de un aparejo mixto, sin mortero, de mampostería de sillarejo combinada con sillería de granito, que sirve para reforzar las jambas de los vanos, cadena de sillares esquineros. Los sillares de granito dispuestos a seco son reciclados de construcciones romanas y readaptados para servir en los paramentos, las dovelas de los arcos, las esquinas, los vanos y los pilares internos (Arbeiter, 2003: 54; León, 2008, 58). 
Precisamente lo más característico del sistema constructivo de esta iglesia es la presencia de dos hiladas o filas de pilares de las que se conservan tres tramos con arcos, en sentido este-oeste, que generan un edificio de planta rectangular longitudinalmente dividido en tres naves. Los pilares $(79 \mathrm{~cm}$ longitud $\times 57 \mathrm{~cm}$ anchura $\times 95 \mathrm{~cm}$ potencia aprox.) sostienen una arquería que tendría al menos cinco vanos de un metro de luz, y los de los extremos se adosan al muro occidental de cierre del aula. Los cimentos de estos pilares, detectados durante la excavación, están formados igualmente por una hilera de sillares en alzado y reformados por zapatas de cantos rodados $(70 \mathrm{~cm} \times 34 \mathrm{~cm}$ aprox.) (fig. 13). Igualmente significativa, una vez más, es la cantidad de material romano de expolio (cornisas, fustes de columnas, epígrafes, etc.) recuperado por F. de Almeida en este lugar, que sería reutilizado en la iglesia y en el conjunto tardoantiguo.

Tampoco ha sido posible constatar la cabecera donde se ubicaría el altar cristiano documentado que reaprovecha un cipo romano. Su restitución planimétrica como espacio único, recto y exento, debe entenderse como una propuesta basada en otros paralelos arquitectónicos de época tardoantigua, como por ejemplo el sanctuarium de la iglesia de Monte da Cegonha, que reocupa parte de una villa romana (Real, 1995: 17-68; Arbeiter, 2000: 249-263). En contextos urbanos, la mayoría de iglesias adopta una planta basilical de tradición tardorromana (Santa Eulalia de Mérida, basílica del Parc Central de Tarragona; Barcelona, València, Terrassa y El Tolmo de Minateda, entre otras), con una cubrición de bóvedas de cañón y arcos diafragmas, y de medio cañón en ábsides y espacios menores. Tan solo en los grupos episcopales de Barcelona y València del siglo viI encontramos edificios de planta cruciforme con una función funeraria, martirial y de oratorio, a los que quizá podría sumarse el caso de Egitania.

Este tipo de plantas cruciformes para la edilicia eclesiástica peninsular se asimila a una solución arquitectónica concreta, que combina la fábrica de sillería y cubiertas abovedadas de piedra. Del mismo modo, el tipo de pequeñas iglesias de planta cruciforme y nave única (y cabeceras exentas de planta rectangular) que encontramos en Conimbriga y en San Pedro de Mérida, estuvo muy extendido en los ambientes rurales de Lusitania (Montinho das Laranjeiras, Ibahernando, Portera y Monte da Cegonha) y de Gallaecia (Dumio y Mosteiros), y pudo pertenecer a la etapa original de formación de un tipo arquitectónico de época visigoda, que más adelante desarrollarían a gran escala las iglesias mozárabes (portuguesas), caso de Vera Cruz de Marmelar, San Nazaré y São Pedro de Lourosa, entre otras (Real, 2000: 32).

Formando parte del grupo episcopal tardoantiguo existirían otras construcciones no identificadas en el estado actual de conocimientos, como son la domus episcopalis y la ecclesia; no obstante, existen varias propuestas al respecto para su identificación (fig. 14). El palacio episcopal pudo estar amortizado por la Sé-catedral, pues la iglesia de Santa María del siglo IX se construyó sobre un edificio anterior (Fernandes, 2005). El edificio visible actual es un aula basilical con orientación norte-sur, dividida en tres naves transversales al ábside por arquerías sobre columnas que originan siete tramos. La técnica constructiva es sillería junto a material romano de expolio, como son los fustes de columnas que pudieran proceder del templo romano, y las basas que aquí son utilizadas como capiteles. 
Figura 14. Fachada oeste de la

Sé-catedral de Idanha-a-Velha durante las excavaciones de

F. de Almeida. Nótense las primeras hiladas de sillares de una posible construcción romana (C DireçãoGeral do Património Cultura SIPA, online, http://www.monumentos.gov. pt, fototeca n. $\left.{ }^{\circ} 00075825\right)$.

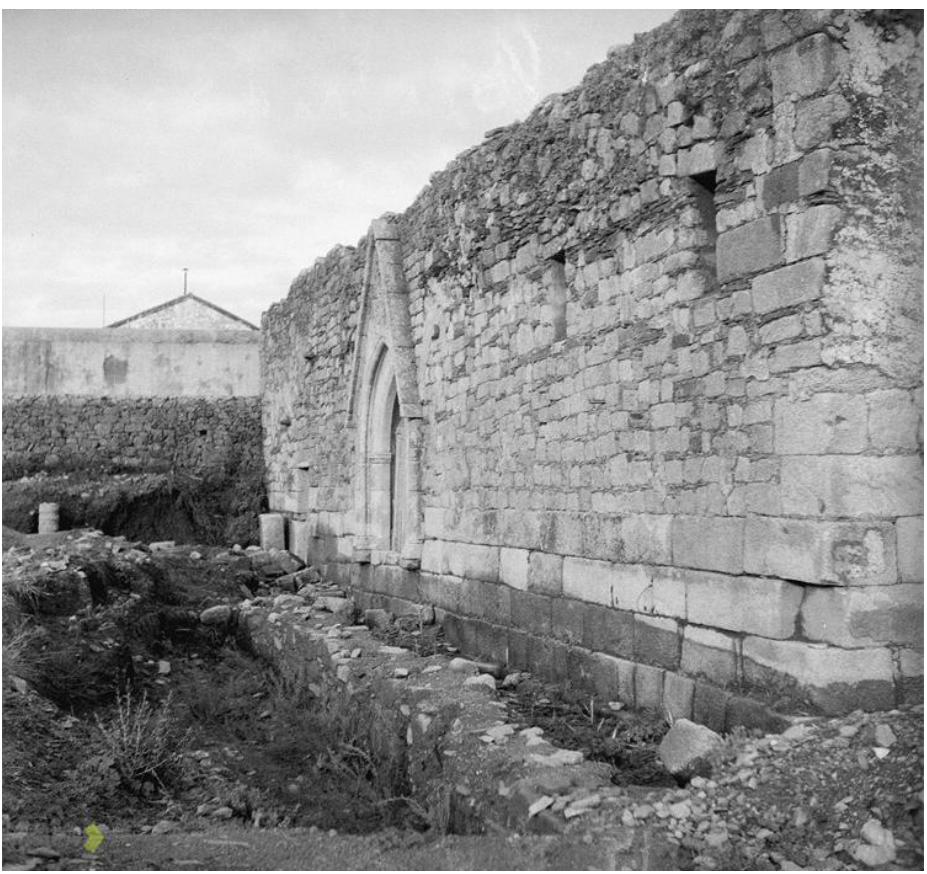

Como habíamos comentado, se conservan varios muros y pavimentos de opus signinum de fases anteriores a la iglesia medieval que definen un edificio de grandes proporciones de planta rectangular, de la que sobresalen dos alas laterales exentas y retranqueadas que confieren a la fachada un aspecto fortificado (fig. 15). Se puede observar con claridad que el muro occidental de la iglesia se asienta sobre varias hiladas de sillares romanos almohadillados, idénticos a los empleados en el templo, y que la misma esquina suroccidental adopta un sistema de engatillado en cremallera. En cuanto a los precedentes catastrales, no se debería desestimar la existencia de un importante edificio — ¿civil?, ¿público? — en la zona con orientación norte-sur, y su reocupación por uno de los edificios de la sede cristiana. Investigadores como L. Caballero han insistido en la irregularidad de su planta, y han señalado que la mayor anchura de la nave occidental en su extremo meridional parece indicar la presencia de una construcción anterior — ¿altoimperial con reocupación en época tardoantigua? - con un piso alto que condicionó el trazado y la disposición de la iglesia medieval (Caballero, 2006: 267).

Dada la monumentalización progresiva que experimenta este espacio desde la aparición del primer baptisterio de la comunidad cristiana local en el siglo v hasta la creación del obispado, cabría situar aquí la domus episcopalis. Las características morfológicas del edificio permiten enmarcarlo dentro de la arquitectura residencial aristocrática tardoantigua. Un buen ejemplo peninsular es el palacio episcopal de Barcino, que, coincidiendo con la 

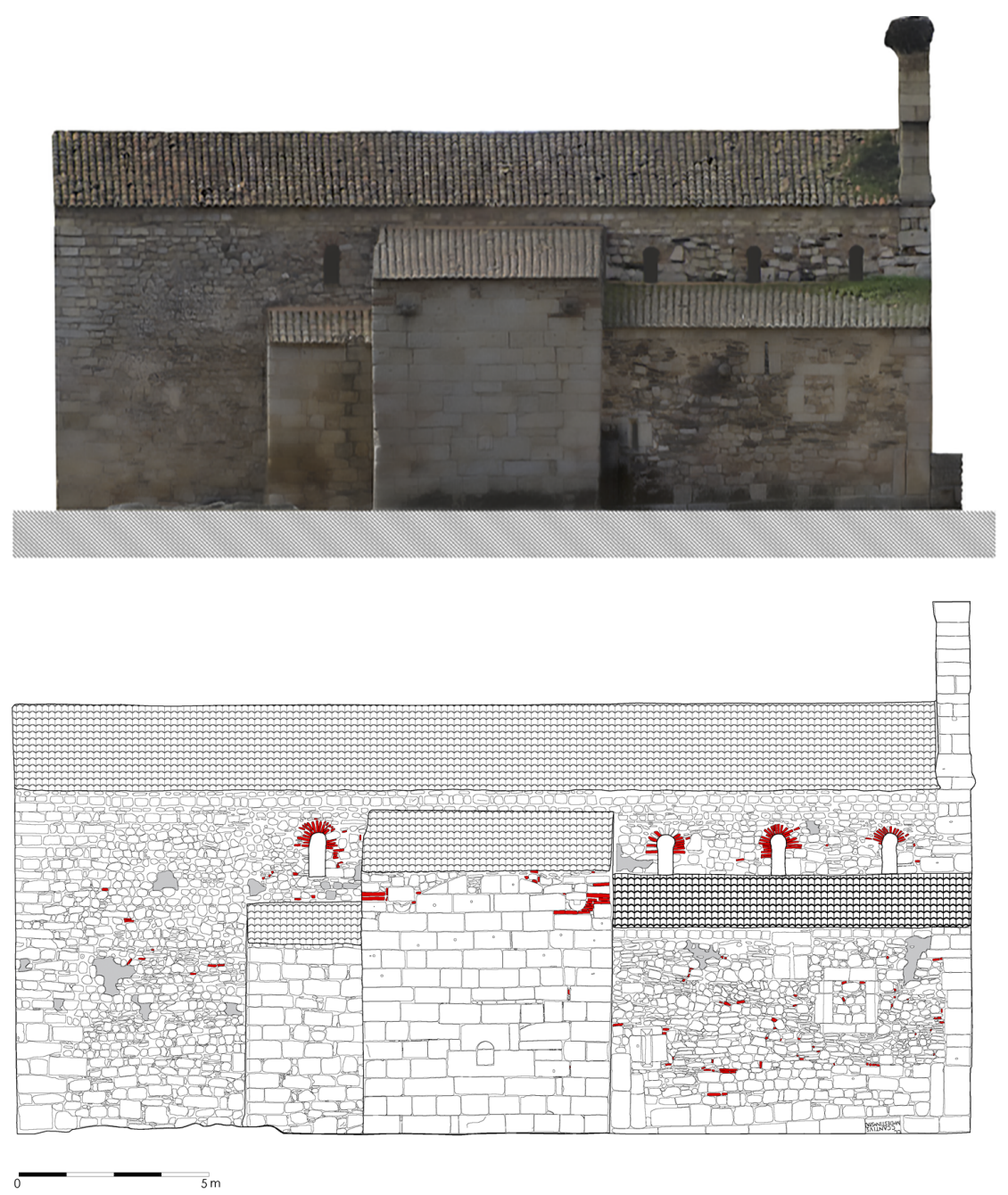

Figura 15. Fotogrametría terrestre de la Sé-catedral. Arriba: Ortoimagen de la fachada oriental tomada con dron. Abajo.: Alzado de la fachada oriental dibujado a partir de ortofotografía vertical anterior (C Proyecto IdaVe).

fase de monumentalización y ampliación del episcopio en la segunda mitad —finales del siglo vI-, se construye sobre la antigua residencia del obispo del siglo v, que ya reocupaba una antigua domus romana situada al norte del baptisterio. El edificio de Barcino también se desarrolla en dos alturas y se organiza a partir de un cuerpo de circulación central, desde el cual se accede a otras dos alas laterales simétricas, que presentan una fachada articulada por un sistema de torres salientes (Beltrán de Heredia, 2018: 79-125). En Emerita Augusta, aunque las V.S.P.E. narran la reforma y el embellecimiento de uno de los espacios del pala- 

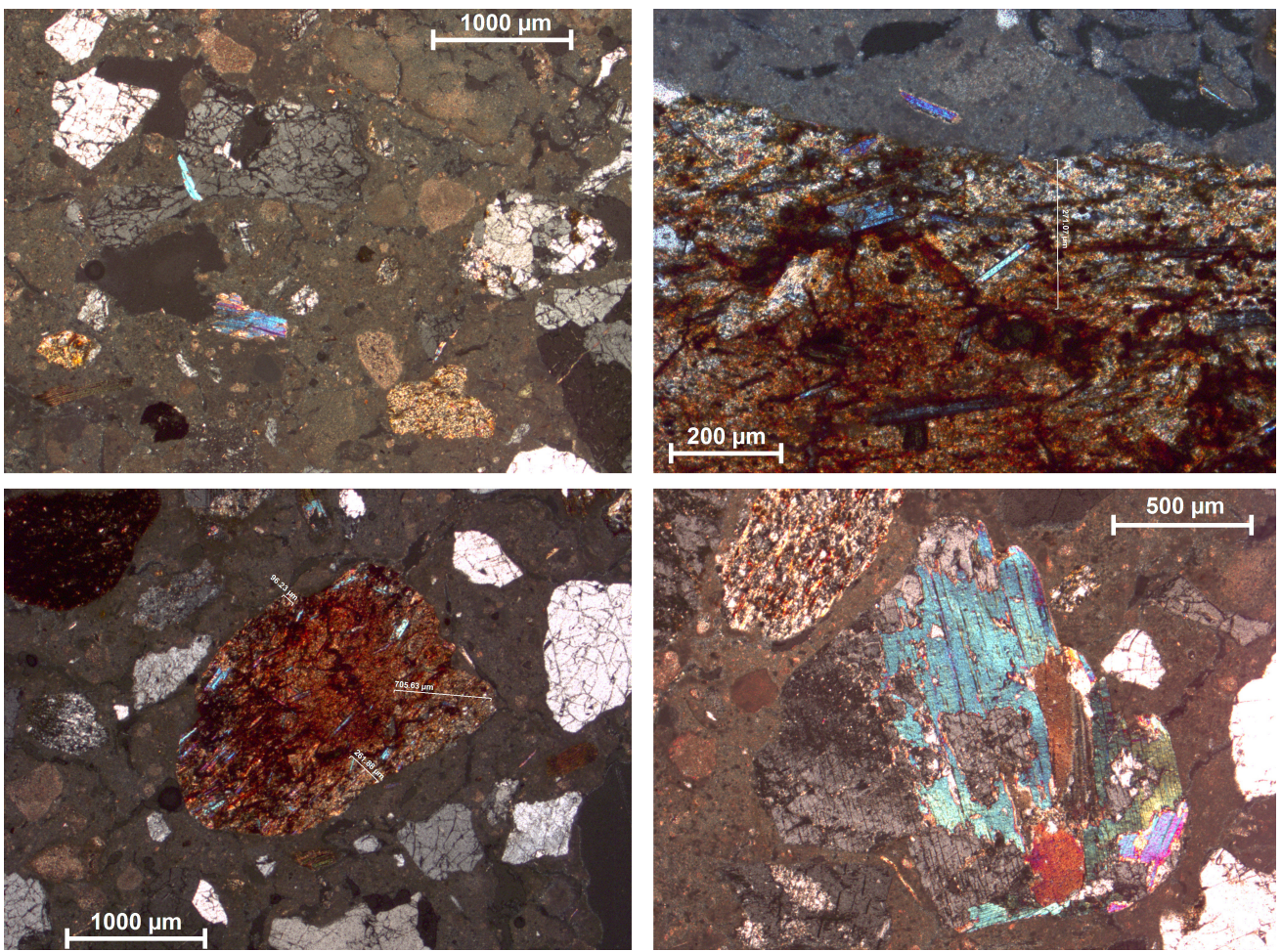

Figura 16. Muestra de mortero 5. Imágenes obtenidas por microscopia óptica donde se observan fragmentos de cerámica de menos de 1000 y presencia de granos de cuarzo muy bien troceados, esquistos y micáceas (C Pablo Guerra, 2013).

cio episcopal tardoantiguo, en concreto del atrium, lo cierto es que no existen testimonios arqueológicos de ese edificio (Maya, 1992: 59).

\subsection{Estudio de los morteros}

Exclusivamente en Idanha-a-Velha se ha realizado un estudio específico de los morteros de algunas de las estructuras del grupo episcopal con el objetivo de determinar la posible relación entre las fábricas documentadas y obtener más información de la manufactura de este material para establecer posibles patrones de fabricación (Guerra, 2015). Tras realizar ocho muestreos recuperados de pavimentos hidráulicos situados en el interior y exterior de la Sé-catedral, un análisis de visu y el procesado de las láminas delgadas, se desarrolló una caracterización macroscópica completa y microscópica óptica de polarización, para determinar la microestratigráfica o granulometría de los áridos, así como una caracterización mineral de algunos de los morteros más significativos (Alonso-Rodríguez, 2002: 151; Broekmans-Maarten, 2009). 
Entre los morteros analizados sobresale el correspondiente a la M5 que fue tomada de un revestimiento presente sobre una fábrica de sillería localizada al exterior de la fachada septentrional (fig. 16). La elección de este mortero se debe a las cualidades técnicas y materiales de la muestra, de factura muy limpia y cuidada. Se trata de un mortero muy bien ejecutado, en el que se ha empleado un árido local mezcla de arena silícea y carbonática al $70 \%-30 \%$, con una gran visibilidad de clastos y granos de cuarzo, siendo estos mayoritarios y de tamaño superior que el resto de muestras.

En líneas generales, el análisis de las argamasas ha permitido determinar que el conglomerante principal utilizado fue la cal, bien decantada y seleccionada. También se han identificado tanto morteros de árido silíceo y cerámico, como emplastos de arcilla y calcita, con granulometrías muy distintas entre estructuras, lo que implica varias fases de reparaciones y construcciones. La transformación de la ciudad romana de Idanha-a-Velha en la Antigüedad tardía no solo afectó la topografía y sus edificios, sino también los materiales estructurales y el resto de técnicas, como la fabricación de morteros, argamasas y revestimientos. Por tanto, la citada diversidad de morteros no sería inusual, ya que se ha documentado también en Conimbriga, donde la caracterización arqueométrica de los morteros ha abarcado un estudio completo y exhaustivo de las argamasas (Guerra y Díaz, 2014).

Los análisis de macroscopia concluyen que las argamasas varían desde una excepcional calidad (M5) a simples emplastos arcillosos (M6 y M8). A pesar de que las Ml y M3 podrían ser manufacturas romanas, no se ha podido establecer una relación calidadcronología directa de los morteros en función del refinamiento de las argamasas. Todas las muestras presentan áridos de naturaleza silícea de granulometrías entre media y muy fina. Se trata de morteros con un árido denominado cocciopesto y de atributos hidráulicos. No se han registrado elementos que puedan datar con certeza las argamasas, pero la ausencia de gravas, yesos, cementos o adiciones orgánicas, así como la distribución y la morfología de los componentes, podrían apuntar a fabricaciones tardoantiguas-altomedievales. Para confirmar la cronología de los morteros se deberá realizar un análisis de radiocarbono de isótopos de ${ }^{14} \mathrm{C}$ y complementarlo con otros ensayos químicos como la difracción de rayos $\mathrm{X}$ o un SEM-EDX. En este sentido, será necesario confrontarlos con las fechas, aún muy tempranas (133-330) que han aportado los últimos análisis de morteros de los baptisterios (Fernández et al., 2019: 5673). Los resultados alcanzados adquirirán un valor más preciso si en el futuro se constituye un corpus de datos a escala provincial, con el fin de contrastarlos con los morteros de las fábricas tardoantiguas emplazadas en otras ciudades lusitanas.

\subsection{Otros edificios cristianos urbanos e iglesias rurales}

Según se desprende de las fuentes escritas y de la evidencia monumental, el patrimonio arquitectónico de la Iglesia lusitana al final de la Antigüedad tardía llegó a ser muy extenso tras la recepción progresiva de propiedades fruto de la donación de fieles y potentes, especialmente en el territorio controlado por la sede episcopal metropolitana de Mérida (Díaz, 
2003: 136). En la capital emeritense sobresalen varios obispos metropolitanos como principales promotores de los nuevos edificios, caso de Fidel, que restaura el palacio episcopal y la iglesia de Santa Eulalia a finales del siglo vi e inicios del vII, coincidiendo en el tiempo con las obras de ampliación y reforma en otras sedes episcopales hispanas prestigiosas como València, Barcelona y Toledo. Las principales construcciones cristianas urbanas constatadas en Emerita Augusta son la basílica martirial de Santa Eulalia, la iglesia de San Pedro y el xenodochium de Masona (fig. 8).

Desde el punto de vista de las técnicas constructivas, todas ellas se caracterizan por la significativa reutilización de material romano de expolio (sillares de granito en su mayoría), sin que por el momento se hayan podido identificar las edificaciones originarias de procedencia que sirvieron de cantera. Este hecho implicaría la presencia en la ciudad de talleres de canteros especializados en la extracción, el trabajo y la adaptación de los materiales. Por ejemplo, la basílica de Santa Eulalia del siglo vi, de planta basilica de tres naves con transepto y cabecera tripartita (que engloba el tumulus de la mártir), está construida prácticamente con sillares romanos reutilizados y calzados con lajas de pizarra que se acoplan con maestría (Mateos, 1999: 156). Lo mismo sucede en la cripta de los obispos enmarcada en este mismo edificio, donde se reciclaron sillares de granito, y en el ábside rectangular de la iglesia de San Pedro, cuya cubierta se resuelve con una bóveda de cañón (Arbeiter, 2003: 75). Un edificio singular, tanto en la ciudad como en el contexto hispano peninsular, es el xenodochium, hospital y albergue situado en las inmediaciones de Santa Eulalia, junto a la vía Emerita-Metellinum, cuya construcción se atribuye al obispo Masona (circ. 571/573-605), siempre según las V.P.S.E. (Maya, 1992). El edificio tiene una planta rectangular configurada por dos corredores porticados abiertos a un patio, con un posible piso superior dada la solidez de sus cimientos a base de grandes sillares, que se desarrollan de manera simétrica a ambos lados de un aula central absidada de una sola altura. Esta última está construida igualmente con material reutilizado, como muestran los rebajes en los sillares de granito que se calzan con lajas de pizarra y la presencia de varias inscripciones funerarias (Mateos, 2003: 91). Incluso la decoración arquitectónica recuperada, caso de las pilastras decoradas de gran tamaño, se realizó sobre bloques romanos expoliados.

Por tanto, una de las prácticas constructivas que caracterizan la arquitectura tardoantigua de Mérida es el uso de sillares romanos reutilizados, enrasados y acuñados con lajas de pizarra, formando cadenas de sillares embutidos en los muros en el caso de los cimientos corridos para soportar arcadas de columnas o pilastras, y el empleo indistinto de fragmentos de epitafios, placas de mármol, fustes y basas. Podemos concluir que los promotores de los conjuntos tardoantiguos emeritenses, al igual que en Egitania, tuvieron a escala local el poder suficiente para desmantelar los edificios romanos y usar sus materiales; pero estos no gozaron de la capacidad o los recursos necesarios para la explotación de las canteras y la producción de elementos constructivos ex novo, que, por el contrario, sí caracterizan las fundaciones áulicas ligadas a la monarquía visigoda en el entorno de la sede regia toletana (p.e., San Pedro de Mata y Santa María de Melque). 
En otro orden de cosas, y sin pretender realizar un inventario exhaustivo, pues excede el contexto de estudio de este trabajo, no queremos obviar referirnos a las características constructivas de los edificios religiosos rurales, monasterios e iglesias, que completaron esta realidad urbana en 'construcción', al ser otros puntos de referencia espacial relevantes para la administración de un territorio, normalmente gestionado por una sede episcopal y por unos poderes políticos. Las iglesias rurales lusitanas, por tanto, constituyen un conjunto arqueológico amplio que, en su mayoría, se ha identificado con parrochiae de función bautismal, litúrgica y funeraria. Se suman las iglesias privadas, a veces con baptisterio, y casi siempre con presencia de contextos funerarios, construidas en antiguas villae romanas (Chavarría, 2006: 17-35), entre las que destacan centros cristianos de estructuración compleja como el de Torre de Palma (Portugal), pues es un ejemplo excelente de la expresión monumental de la cristianización de las élites en el territorio (Maloney, 1995: 449-458). Todas estas construcciones fueron unidades básicas en la organización episcopal, si bien entre sus promotores o evergetas se documentan potentes laicos como el noble Pascentium (Wolfram y Sastre de Diego, 2015: 1900).

Al igual que en los espacios urbanos analizados, en la construcción de los edificios religiosos rurales se utilizó material romano expoliado de carácter constructivo (sillares, fustes, capiteles, basas), escultórico (placas), latericio (tegulae, baldosas, ladrillos) y epigráfico (inscripciones conmemorativas y funerarias). La técnica constructiva predominante es la mampostería de granito (San Benito) (Alba, 2003a: 108) o de pizarra local para los alzados (Ibahernando) (Cerrillo, 2003: 65), normalmente en alternancia con material latericio romano reaprovechado (El Gatillo); el uso específico de bloques/sillares de granito en los ángulos, caso de Valdecebadar (Ulbert, 2003: 97), Santa Lucía de Salvatierra (Alba, 2003b: 100) y San Benito, y para los contrafuertes, cimentaciones y en zonas destacadas de la construcción, como la cabecera (Ibahernando). La presencia de sillares que son cortados y enrasados para maximizar su correcto aprovechamiento (Santa Lucía del Trampal, San Miguel de los Fresnos) (Arbeiter, 2003: 50) es una técnica constructiva que encuentra sus paralelos en otras iglesias relevantes del centro peninsular (La Nave, Quintanilla de las Viñas y Baños). Del mismo modo, se observa el empleo de placas epigráficas de acarreo como umbrales de puertas y de canceles (Ibahernando, Santa Lucía del Trampal, El Gatillo). La iglesia monástica de Santa Lucía del Trampal sobresale especialmente por la reutilización masiva en la fábrica de sus muros de unos cincuenta epígrafes romanos, votivos y estelas funerarias, de un posible santuario dedicado a Ataecina, que se encontraría en las inmediaciones (Caballero, 2003: 16) (fig. 17). Otra inscripción de Ataecina junto a un ara funeraria de granito estaban embutidas en los muros de la iglesia de Santa Lucía de Salvatierra, con alzados de mampostería irregular y sillares reutilizados en las esquinas. Igualmente interesante es la reutilización de sillares moldurados romanos en una iglesia tardoantigua ubicada extramuros de Coria, que fueron retallados, y colocados a tizón y calzados con pizarras. Se han conservado hasta cuatro hiladas en altura de este edificio de planta basilical con tres naves separadas por arquería sobre pilares, cubierta a dos aguas y ábside exento de herradura de 3,08 m diámetro, según el mismo esquema constructivo que 


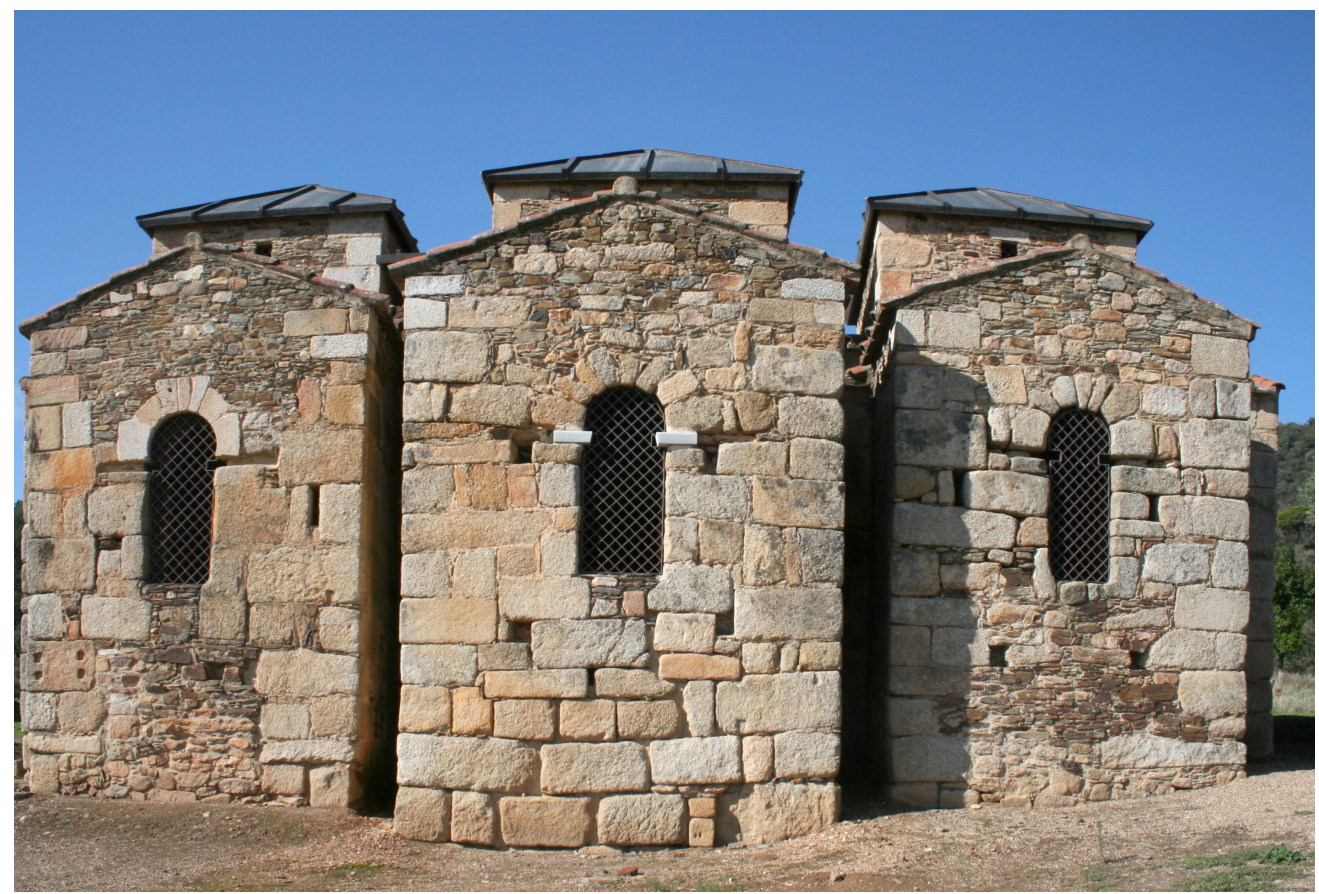

Figura 17. Fachada oriental de la iglesia de Santa Lucía del Trampal (Alcuéscar, Cáceres), correspondiente a la cabecera. Nótese la técnica constructiva en opera mixta (C) autora).

en la basílica de Santa Eulalia de Mérida. En época medieval, la reutilización de material de expolio continuó siendo una práctica frecuente. Es el caso de la iglesia de São Pedro de Lourosa (Conimbriga), fechada en el siglo x, que emplea sillería de granito, basas, fustes y capiteles romanos reutilizados que pudieron ser trasladados desde el asentamiento romano de Bobadela (Utrero, 2012: 134).

\section{Conclusiones}

Las nuevas perspectivas metodológicas que se han impuesto en la práctica e investigación arqueológica han permitido proponer nuevas interpretaciones más allá de lo que implicó la fundación de un edificio. Es fundamental conocer el porqué de la inserción de las estructuras religiosas en el paisaje, ya que la distribución de las iglesias está relacionada con los agentes locales urbanos y la organización del poblamiento, en el caso del territorio. Cuestiones importantes sobre su monumentalitas siguen presentes en el debate actual, quizás ahora ya reorientado a resolver, o a plantearse, otras nuevas problemáticas 
relacionadas con sus promotores, constructores, costes, etc. Los métodos empleados para el estudio de las técnicas constructivas han sabido adaptarse al cambio experimentado por la investigación en este sentido, y ha permitido profundizar en el conocimiento de su proyecto y construcción, y completar las cronologías e información aportadas por la excavación estratigráfica.

Por lo que respecta a este trabajo en concreto, hemos intentado afrontar la problemática de una supuesta existencia de 'modelos' arquitectónicos urbanos para las arquitecturas relacionadas con las élites tardoantiguas en la Lusitania. Como caso de estudio novedoso, hemos presentado los resultados alcanzados en el proyecto sobre la ciuitas Igaeditanorum y posterior sede episcopal de Egitania, con miras a contextualizar su realidad en el marco urbano de la Lusitania, y compararla sobre todo con Emerita Augusta y Myrtilis, por ser las únicas dos ciudades con mayor investigación en el tema de estudio. Tras haber realizado un análisis formal y tecnológico de las fábricas de las estructuras preservadas, de las soluciones constructivas y de los materiales empleados, se concluye con evidencia que existe una característica común de las técnicas que las definen a todas ellas: los spolia. La identificación del acopio de elementos decorativos y arquitectónicos de los edificios previos, empleados bien con una intencionalidad simbólica (Schattner, 2009: 103) bien como simple material constructivo (Liverani, 2004: 383-434), es interesante y altamente significativa por sí misma, pues está indicando cambios urbanos, constructivos, sociales y económicos, y se documenta en todo el Mediterráneo romano a partir de la Antigüedad tardía. No obstante, no siempre se reutiliza material a pesar de su disponibilidad (Brilliant y Kinney, 2011). ¿Qué determina en última instancia la reutilización o no de materiales en las nuevas construcciones?

En primer lugar, la reutilización de material romano en las nuevas construcciones es el fenómeno que caracteriza el proceso productivo y arquitectónico en la Lusitania tanto en contextos urbanos como rurales. Durante el proceso de construcción de los nuevos edificios de Egitania (muralla y el grupo episcopal) se recurre especialmente al reciclaje y la reutilización de fustes de columnas, placas decorativas, frisos e inscripciones procedentes de edificios romanos. En realidad, desconocemos las particulares locales del proceso de expolio en la ciuitas Igaeditanorum (¿favorecido tras la concurrencia de un terremoto?, ¿quién lo encarga y ejecuta?), pero las construcciones de origen estarían lógicamente ya abandonadas y sin función. Algo de luz arrojan ejemplos como Colonia Patricia Corduba, donde el teatro romano y una parte de la mitad meridional de la ciudad quedaron destruidos tras los efectos de un terremoto el tercer tercio del siglo III. El complejo monumental de Cercadilla, construido a inicios del siglo iv en la zona septentrional extramuros se nutrió de material expoliado de los edificios devastados por el seísmo, entre ellos el teatro ya citado (Ventura y Pizarro, 2010: 199-200; Morín et al., 2014: 160).

Tampoco se han podido identificar con precisión en la ciuitas Igaeditanorum la funcionalidad y las características constructivas y formales de los edificios de origen. Se está realizando actualmente un estudio de proporciones y metrología para confirmar si los fustes de granito de la columnata de la Sé-catedral, que ya habrían sido reutilizados en el 
posible palacio episcopal egitano, proceden del templo altoimperial del foro romano. La Iglesia sería el único poder local capaz, que podamos señalar, responsable de esta actividad orientada a la recuperación de materiales para el abastecimiento de la nueva arquitectura eclesiástica.

Al margen de los spolia, y dado que el muestreo se reduce a unos pocos edificios, resulta difícil establecer un estereotipo predominante en cuanto a tipologías arquitectónicas — caracterizadas por la heterogeneidad de las plantas y los modelos-y profundizar en las estructuras socioeconómicas del entorno en el que se realizaron, así como definir el grado de especialización del artesanado que las ejecutó. Por tanto, hay que seguir trabajando para responder a estas problemáticas y a otras cuestiones inherentes al proyecto arquitectónico, como la inversión temporal en la extracción, el transporte y la readaptación de los materiales romanos de expolio, y algunas más específicas sobre la circulación de modelos arquitectónicos y cuáles fueron los edificios romanos explotados como cantera.

En segundo lugar, recordaremos que las dinámicas urbanísticas en las ciudades lusitanas de la Antigüedad tardía conllevaron profundos cambios morfológicos, topográficos e ideológicos de manera progresiva a partir del siglo IV, desencadenados a su vez por la irrupción de una variedad de nuevos factores como la expansión del cristianismo, cambios medioambientales, además de los ya 'tradicionales' argumentos de orden económico, social y político. Todo ello generó un nuevo concepto urbano dirigido también por nuevos e inestables poderes locales en el que se desatienden las infraestructuras urbanas, se abandonan y/o reocupan muchos de los edificios y espacios de la ciudad clásica con otros fines. Además, en todas las ciudades se repite un mismo esquema urbano: la ciudad fortificada. El amurallamiento a inicios del siglo iv es uno de los fenómenos más tempranos constatado en centros urbanos estratégicos que ejercieron un poder económico sobre su territorio. Si las murallas ya existen, se reforman; de lo contrario, los poderes locales las construyen, normalmente con material expoliado. Más complejo resulta responder qué motivó este fenómeno, para el que, autores como K. Bowes, reflejaría un reforzamiento de la presencia imperial (burocrática y militar) en esta zona del 'Far West', por causas aún más complejas de explicar, entre las que se han señalado la intensificación y la mejora del control en la recaudación de tributos en efectivo (Bowes, 2013: 213). No olvidemos que esta situación coincide con una mayor concentración de sedes episcopales en la zona septentrional de la Lusitania.

Finalmente, más allá de la ciudad, la arquitectura eclesiástica en el campo es otro de los canales básicos para comprender la gestión de los recursos económicos de un territorio (población y producción) y el mantenimiento del patrimonio latifundista por parte de la Iglesia y las aristocracias laicas. Las élites lusitanas intervinieron también en la transformación del paisaje rural a través de la fundación de iglesias y nuevos conjuntos eclesiásticos (monásticos) y funerarios. En la diócesis egitana no se han constatado arqueológicamente complejos cristianos, y la mayoría de las iglesias conocidas pertenecieron al obispado emeritense. La aportación principal al conocimiento de la arquitectura eclesiástica y rural tardoantigua corresponde a la publicación del Repertorio de arquitectura cristiana en 
Extremadura (Mateos y Caballero, 2003). Esta monografía debería ser punto de partida fundamental para futuras investigaciones que deseen alcanzar unas conclusiones sólidas y diversificadas sobre la circulación de proyectos y modelos arquitectónicos, estudio de paisajes, técnicas constructivas e influencia de los arquitecturas episcopales en el campo, entre otras cuestiones.

\section{Agradecimientos}

El trabajo presentado en esta revista ha sido posible gracias a la ayuda de diferentes instituciones y personas. Parte de este estudio se ha realizado durante el proyecto Urban landscape of power in the Iberian Peninsula from Late Antiquity to the Early Middle Ages, que ha recibido financiación de la Comisión Europea en el marco de las Marie Skłodowska-Curie Actions 'Horizon 2020-MSCA-IF-EF-ST-2016' y está siendo desarrollado por Isabel Sánchez gracias al 'Grant Agreement No. 740123'. Los resultados alcanzados sobre las técnicas se enmarcan en el proyecto I+D La arquitectura romana de la Lusitania. Producción y economía de los procesos de perduración, trasformación e innovación técnica (HAR2015-64392-C4-3-P), dirigido por Antonio Pizzo y financiado por el Ministerio de Economía y Competitividad (2016-2019). Las investigaciones de Idanha-a-Velha forman parte del PIPA de la Direçao Genéral do Património de Portugal bajo el título Paisajes culturales de la sede episcopal de Egitania en época tardoantigua (2012-2019). El proyecto ha recibido financiación en 2015 y 2017 del Ministerio de Cultura en su programa de «Ayudas para Proyectos de Excavación en el Exterior» (ref. G-45206596), con el respaldo institucional de la Real Fundación Toledo. Sirva esta publicación para reconocer la perseverancia y el esfuerzo de un equipo profesional y humano excepcional, por su incondicional apoyo y participación. A todos ellos, especialmente a Jorge Morín, mi más sincero agradecimiento.

\section{Bibliografía}

ALARCÃO, J., 1998, On the Ciuitates mencioned in the inscription on the bridge at Alcântara, Journal of Iberian Archaeology 0, 143-157.

ALARÇÃO, P., 2008, Conservación y puesta en valor de las ruinas de Conímbriga, III Bienal de Restauración Monumental: sobre la des-Restauración 3, Junta de Andalucía, Sevilla, 649-655.
ALBA, M., 2003a, Iglesia de San Benito, San Vicente de Alcántara, en P. MATEOS y L. CABALLERO (eds.), Repertorio de arquitectura cristiana en Extremadura. Época tardoantigua y altomedieval, Anejos de AEspA XXIX, Mérida, 107-108. 
ALBA, M., 2003b, Iglesia de San Miguel de los Fresnos, Fregenal de la Sierra, en P. MATEOS y L. CABALLERO (eds.), Repertorio de arquitectura cristiana en Extremadura. Época tardoantigua y altomedieval, Anejos de AEspA XXIX, Mérida, 49-51.

ALMEIDA, F., 1956, Egitania. História e arqueología, Lisboa.

ALMEIDA, F.,1966, Um palatium episcopi do sec. vi em Idanha-a-Velha (Portugal), IX Congreso Nacional de Arqueología: Valladolid, Burgos, Palencia, Santander, 17-21 de octubre 1965, Zaragoza, 408-411.

ALMEIDA, F. y FERREIRA, O. da V., 1957, Notas sobre as primeiras excavações em Idanha-a-Velha, XXIII Congreso luso-espanhol para o progresso das Ciências, 7. a secção, Associação Portuguesa para o Progresso das Ciências, Coimbra, 9-14.

ALONSO, F.C., 2002. Ensayos físicos de caracterización y comportamiento de materiales, en P. GISBERT (ed.-coord.), I Jornadas de Caracterización y Restauración de Materiales Pétreos en Arquitectura, Escultura y Restauración I, Zaragoza, 149-169.

ALONSO, F., RODRÍGUEZ, E. y RUBINO, A., 2004, Datación de madera constructiva en San Pedro de la Nave (Zamora) y su interdatación con San Juan de Baños (Palencia), en L. CABALLERO (coord.), La iglesia de San Pedro de la Nave. Zamora, Zamora, 209-237.

ARBEITER, A., 2000, Alegato por la riqueza del inventario monumental hispanovisigodo, en L. CABALLERO y P. MATEOS (eds.), Visigodos y Omeyas. Un debate entre la Antigüedad Tardía y la Alta Edad Media, Anejos de AEspA XXIII, Madrid, 249-263.

ARCE, J., 2002, Mérida tardorromana (300-580 d.C.), Mérida.

ARCE, J., 2003, Augusta Emerita en los siglos Iv-v d.C.: La documentación escrita, en P. MATEOS y L. CABALLERO (eds.), Repertorio de arquitectura cristiana en Extremadura: época tardoantigua y altomedieval, Anejos de AEspA XXIX, Mérida, 121-132.
ARCE, J., 2011, Esperando a los árabes. Los visigodos en Hispania (507-711), Madrid.

ARCE, J., 2012, Campos, tierras y villae en Hispania (siglos IV-VI), en L. CABALLERO, P. MATEOS Y T. CORDERO (eds.), Visigodos $y$ Omeyas. El territorio, Anejos de AEspA LXI, Madrid, 21-30.

AYERBE, R. y MATEOS, P., 2015, Un nuevo ejemplo de arquitectura pública emeritense en época tardoantigua, en J. GARCÍA, I. MAÑAS y F. SALCEDO (eds.), Navigare necesse est. Estudios en homenaje a José María Luzón Nogué, Madrid, 179-191.

BAPTISTA, J., Carta arqueológica da freguesia de Idanha-a-Velha. Preservação 17, Vila Velha de Ródão.

BARROSO, R., CARROBLES, J., DIARTE, P. y MORÍN, J., 2013, Obispos y reyes. Evolución del territorio ercavicense desde la tardía antigüedad a época visigoda: El monasterio Servitano y la ciudad regia de Recópolis, Concavis Petrarum habitaverunt: el fenómeno rupestre en el Mediterráneo medieval (Museo de los Orígenes, 18-19 de diciembre de 2008), BAR Internacional Series S1720, Oxford, 257-308.

BELTRÁN DE HEREDIA, J., 2017, Los nuevos hallazgos arqueológicos de la basílica dels Sants Màrtirs Just i Pastor y la dualidad de baptisterios en Barcelona, en J. BELTRÁN y C. GODOY (eds.), La dualidad de baptisterios en las ciudades episcopales del cristianismo tardoantiguo, Studia Archeologiae Christianae 2, Barcelona, 99-126.

BELTRÁN DE HEREDIA, J., 2018, Barcelona, la topografía de un centro de poder visigodo: católicos y arrianos a través de la arqueología, en I. SÁNCHEZ y P. MATEOS (eds.), Territorio, topografía y arquitectura de poder durante la Antigüedad tardía, serie Mytra 1, Mérida, 79-125.

BONNAUD, C., 2001, L'administration du territoire vetton à l'époque romaine: status juridiques et institutions, Conimbriga 40, 5-35.

BOWES, K., 2013, Villas, taxes and trade in fourth century Hispania, en L. LAVAN (ed.) Local Economies? Production and Exchange of Inland Regions 
in Late Antiquity, Late Antique Archaeology 10, Leiden, 191-226.

BRILLIANT, R. y KINNEY, D., 2011 , Reuse Value. Spolia and Appropriation in Art and Architecture from Constantine to Sherrie Levine, Ámsterdam.

BROEKMANS-MAARTEN, A.T.M., 2009, Petrography as an essential complementary method in forensic assessment of concrete deterioration: two case studies, Materials Characterization 60, 644-654.

BROGIOLO, G.P., 2012, De "Aristocrazie e Campagne" a una arqueología de los paisajes medievales, en L. CABALLERO, P. MATEOS y T. CORDERO (eds.), Visigodos y Omeyas. El Territorio, Anejos de AEspA LXI, Mérida, 9-20.

CABALLERO, L., 2003, La Iglesia de Santa María del Trampal. Alcuéscar, en P. MATEOS y L. CABALLERO (eds.), Repertorio de arquitectura cristiana en Extremadura. Época tardoantigua y altomedieval, Anejos de AEspA XXIX, Mérida, 15-20.

CABAllero, L., 2006, Aportaciones de la lectura de paramentos a la polémica sobre la Sé de Idanha-a-Velha, Al-Ãndalus espaço de mudança. Balanço de 25 anos de história e arqueología medievais. Homenagem a Juan Zozaya Stabel-Hansen. Seminário Internacional, Mértola 16, 17 e 18 de maio de 2005, Mértola, 266-273.

CARVALHO, P.C., 2007, Cova da Beira. Ocupação e exploração do território na época romana (um território rural no interior norte da Lusitania), Fundão-

Coimbra.

CARVALHO, P.C., 2009, O forvm dos igaeditani e os primeiros tempos da ciuitas igaeditanorum (Idanha-a-Velha, Portugal), Archivo Español de Arqueología 82, Madrid, 115-131.

CERRILLO, E., 2003, Iglesia de Ibahernando, Magasquilla de los Donaire, en P. MATEOS y L. CABALLERO (eds.), Repertorio de arquitectura cristiana en Extremadura. Época tardoantigua y altomedieval, Anejos de AEspA XXIX, Mérida, 63-167.

CHAVARRÍA, A., 2006, Villas en Hispania durante la Antigüedad tardía, en A. CHAVARRÍA, J. ARCE y G. P. BROGIOLO (eds.), Villas Tardoantiguas en el Mediterráneo Occidental, Anejos de Archivo Español de Arqueología XXXIX, Madrid, 17-35.

CHAVARRÍA, A., 2007, Aristocracias tardoantiguas y cristianización del territorio (siglos IV-v): ¿otro mito historiografico?, Rivista di Archeologia Cristiana LXXXII, 201-230.

CORDERO, T., 2018, Egitania: ciudad y territorio durante el periodo suevo-visigodo, Fortificaciones, poblados y pizarras. La Raya en los inicios del Medievo, Catálogo de Exposición, Ciudad Rodrigo, 110-120.

CÔRTE-REAL, A. y POLICARPO, I., 1996, Idanhaa-Velha, Processo de Classificação, Coimbra.

CRISTÓVÃO, J. L., 2002, As muralhas romanas de Idanha-a-Velha, Coimbra.

CRISTÓVÃO, J. L., 2005, Breve estudo sobre a organizão do espaço público e os equipamentos urbanos da cidade romana de Idanha-a-Velha (dos finais do século i a.C. ao limiar do século iv), Lusitanos e Romanos no Nordeste da Lusitânia. Actas das $2{ }^{\text {as }}$ Jornadas de Património da Beira Interior, Guarda, 21 a 22 de outubro de 2004, Guarda, 189-206.

DIARTE, P., 2012, La configuración urbana de la Hispania tardoantigua: Transformaciones y pervivencias de los espacios públicos romanos (s. III-VI d.C.), BAR International Series 2429, Oxford.

DIARTE, P. y CHRISTIE, N. (eds.), 2018, Interpreting transformations of people and landscapes in Late Antiquity and the early Middle Ages: archaeological approaches and issues, Barnsley.

DÍAZ, P., 2003, La iglesia lusitana en época visigoda: la formación de un patrimonio monumental, en P. MATEOS y L. CABALLERO (eds.), Repertorio de arquitectura cristiana en Extremadura: época tardoantigua y altomedieval, Anejos de AEspA XXIX, Mérida, 133-143.

FERNANDES, P., 2001, A Mesquita-Catedral de Idanha-a-Velha, Cadernos de Ciência das Religiões 4, Lisboa.

FERNANDES, P., 2005, Eclectismo. Classicismo. Regionalismo. Os caminhos da arte cristã no Ocidente peninsular entre Afonso III e al-Mansur, en M. BARROCA e I.C. FERNANDES (eds.), 
Muçulmanos e Cristãos entre o Tejo e o Douro (séculos VIII a XIII), Câmara Municipal de Palmeia e Faculdade de Letras da Universidade do Porto, Oporto, 293-310.

FERNÁNDEZ, A.F., CARVALHO, P.C.,

CRISTÓVÃO, J., SANJURJO-SÁNCHEZ, J. y DIAS, P., 2019, Dating the early Christian baptisteries from Idanha-a-Velha. The Suebi-Visigothic Egitania: stratigraphy, radiocarbon and OSL, Archaeological and Anthropological Sciences 11, 56915704.

GARCIA, M. G., MORO, A. y TUSET, F., 2009, La seu episcopal d'Ègara. Arqueologia d'un conjunt cristià del segle IV al IX, Sèrie Documenta, 8, Tarragona.

GIL, V., 1999, O espaço urbano nas cidades do norte da Lusitânia, en A. RODRÍGUEZ (coord.), Los orígenes de la ciudad en el Noroeste hispánico, Congreso Internacional, Lugo 15-18 de mayo 1996, vol. II, Lugo, 355-391.

GINER, J. L., SILVA, P., PÉREZ, R., RODRÍGUEZPASCUA, M. A., BARDAJÍ, T., GARDUÑO, V. H. y LARIO, J., 2011, Evaluación del daño sísmico en edificios históricos y yacimientos arqueológicos. Aplicación al estudio del riesgo sísmico. Proyecto EDASI. Serie Investigación, Fundación MAPFRE, Madrid.

GINER, J., PÉREZ, R., SILVA, P. RODRÍGUEZPASCUA, M. A., MARTÍN, F. Y CABAÑAS, L., 2012, Análisis estructural de daños orientados en el terremoto de Lorca del 11 de mayo de 2011. Aplicaciones en Arqueosismologia, Boletín Geológico y Minero de España 123/4, 503-513.

GINER, J., PÉREZ, R., RODRÍGUEZ-PASCUA, M. A, SILVA, P. MARTÍN, F. y RODRÍGUEZ, E., 2013, A review on oriented fall structures (Earthquake Archaeological Effect, EAE) induced by instrumental earthquakes, Cuaternario $y$ Geomorfología 27/3-4, 37-49.

GONZÁLEZ, L., 2008, Las explotaciones mineras romanas en Hispania, en T. NOGALES y P. FERNÁNDEZ (eds.), Ciencia y tecnología en el mundo antiguo, Monografías emeritenses 8, Mérida.

GUERRA, P., 2015, Sola Romani. Los morteros hidráulicos romanos en la Península Ibérica, Universidad Politécnica de Madrid (tesis doctoral inédita).
GUERRA, P. y DÍAZ, S., 2014, Los morteros en la investigación arqueológica, IV Jornadas del Foro Ibérico de la Cal, 8 y 9 de mayo de 2014, 1, Madrid, 141-150.

GURT, J. M. e HIDALGO, R., 2005, L'urbanisme a la ciutat hispana al llarg de l'Antiguitat tardana, en J.M. GURT y A.V. RIBERA (eds.), VI Reunió d'Arqueologia Cristiana Hispànica. Les ciutats tardoantigues d'Hispania: cristianització i topografia, València, 8-10 de maig de 2003, Barcelona, 73-93.

GUTIÉRREZ, S. y SARABIA, L., 2013, The episcopal complex of Eio-El Tolmo de Minateda (Hellín, Albacete, Spain). Architecture and spatial organization. $7^{\text {th }}$ to $9^{\text {th }}$ centuries AD, Hortus Artium Medievalium 19, 267-300.

GUTIÉRREZ, J. A., 2014, Fortificaciones tardoantiguas y visigodas en el Norte peninsular (ss. v-VIII), en R. CATALÁN, P. FUENTES y J. C. SASTRE (eds.), Las fortificaciones en la Tardoantigüedad. Élites y articulación del territorio (siglos V-VIII d.C.), Madrid, 191-214.

HINZEN, K., FLEISCHER, C., REAMER, K., SCHREIBER, S., SCHÜTTE, S. y YERLI, B., 2011 , Quantitative methods in archaeoseismology, Quaternary International 242, 31-41.

HUGHES, J. y CALLEBAUT, K., 2000, Practical sampling of historical mortars, en P. BARTOS, C. GROOT y J. HUGHES (ed.), Proceedings of the RILEM International Workshop Historic Mortars: characteristics and tests, Paisley, 17-26.

KORJENKOV, A.M. y MAZOR, E., 2013, The Features of the Earthquake Damage Patterns of Ancient City Ruins in the Negev Desert, Israel, Geotectonics 47, 52-65.

LEON, A. 2008, La construcción en sillería en España durante la Alta Edad Media. Una revisión de la información arqueológica, Archeologia Medievale XXXV, 55-74.

LIVERANI, P., 2004, Reimpiego senza ideologia: la lettura antica degli spolia dall'arco di Costantino all'età carolingia, Römische Mitteilungen 111, 383-434.

LOPES, V., 2004, Mértola na antiguidade tardia. A topografia histórica da cidade e do seu território nos alvores do cristianismo, Mértola. 
LOPES, V., 2017, Mértola na antiguidade tardia. A topografia histórica, Arqueologia em Portugal. Estado da Questão, Lisboa, 1379-1390.

LOPES, V. y MACIAS, S., 2005, Mértola na Antiguidade Tardia, en J. M. GURT y A. V. RIBERA (eds.), VI Reunió d'Arqueologia Cristiana Hispànica. Les ciutats tardoantigues d'Hispania: cristianització i topografia, València, 8-10 de maig de 2003 , Barcelona, 449-464.

MACIEL, M. J. y CAMPOS, T. C., 1994, A basílica e o baptisterio paleocristãos de Conimbriga, III Reunión de Arqueología Cristiana Hispánica. Maó 1988, Barcelona, 75-92.

MALONEY, S. J., 1995, The early christian basilican complex of Torre de Palma (Monforte, Alto Alentejo, Portugal), en J. M. GURT y N. TENA (eds.), IV Reunión de Arqueología Cristiana Hispánica, Barcelona, 449-458.

MANTAS, V.G.S., 1988, Orarium donavit Igaiditanis: epigrafia e funções urbanas numa capital regional lusitana, I Congreso Peninsular de Historia Antigua, Santiago de Compostela 1986, vol. II, Santiago de Compostela, 415-439.

MATEOS, P., 1999, Santa. Eulalia de Mérida. Arqueología y urbanismo, Anejos de AEspA XIX, Madrid.

MATEOS, P., 2003, Xenodochium, Mérida, en P. MATEOS y L. CABALLERO (eds.), Repertorio de arquitectura cristiana en Extremadura. Época tardoantigua y altomedieval, Anejos de AEspA XXIX, Mérida, 89-94.

MATEOS, P., 2004, Topografía y evolución urbana, en X. DUPRÉ (ed.), Las capitales provinciales de Hispania 2. Mérida. Colonia Augusta Emerita, Roma, 27-39.

MATEOS, P. y ALBA, M., 2000, De Emerita Augusta a Mérida, en L. CABALLERO y P. MATEOS (eds.), Visigodos y Omeyas. Un debate entre la Antigüedad Tardía y la Alta Edad Media, Anejos de AEspA XXIII, Madrid, 143-168.

MATEOS, P. y CABALLERO, L. (eds.), 2003, Repertorio de arquitectura cristiana en Extremadura. Época tardoantigua y altomedieval, Anejos de AEspA XXIX, Mérida.
MAYA, A., 1992, Vitas Sanctorum Patrum Emeretensium, Corpus Christianorum CXVI, Turnholt.

MORÍN, J., SILVA, P., RODRÍGUEZ-PASCUA, M.A. y SÁNCHEZ, I., 2014, Evidencias arqueosismológicas en la Colonia Patricia romana de Córdoba (Valle del Guadalquivir, España), Una aproximación multidisciplinar al estudio de las fallas activas, los terremotos y el riesgo sísmico, Segunda Reunión Ibérica sobre Fallas activas y Paleosismología, Lorca, España. Del 22 al 24 de octubre de 2014, 159-162, Madrid.

PIZZO, A., 2016, El puente romano de Alcántara: nueva documentación arqueológica y evidencias constructivas previas, Arqueología de la Arquitectura 13: e038. doi: http://dx.doi.org/10.3989/arq. arqt.2016.023 [consultado online el 20 de julio de 2018].

PIZZO, A., ROLDÁN, L., MACIAS, J. y RODRÍGUEZ, 2017, Modelos constructivos y urbanísticos de la arquitectura de Hispania. Definición, evolución y difusión del período romano a la Antigüedad tardía (MArqHis 2013-2015), Documenta 29, Tarragona.

PLIEGO, R., 2012, La moneda visigoda: Anexo I, Spal 21, 209-231.

POLCI , B., 2003, Some aspects of the transformation of the Roman domus between Late Antiquity and Early Middle Ages, en L. LAVAN y W. BOWDEN (eds.) Theory and Practice in Late Antique Archaeology, Late Antique Archaeology 1, Leiden-Boston, 79-109.

QUIROS, J. A. y FERNÁNDEZ, M., 2012, Para una historia social de la arquitectura monumental altomedieval asturiana, en L. CABALLERO, P. MATEOS y C. GARCÍA DE CASTRO (eds.), Asturias entre visigodos y mozárabes, Anejos de AEspA LXIII, Madrid, 27-53.

REAL, M. L., 1995, Inovação e resistencia: dados recentes sobre a Antiguidade Cristã no ocidente peninsular, en J.M. GURT y N. TENA (eds.), IV Reunión de Arqueología Cristiana Hispánica, Barcelona, 17-68.

REAL, M. L., 2000, Portugal: cultura visigoda y cultura moçárabe, en L. CABALLERO y 
P. MATEOS (eds.), Visigodos y Omeyas. Un debate entre la Antigüedad tardía y la alta Edad Media, Anejos de AEspA XXIII, Madrid, 21-75.

RIPOLL, G., 2009, Corpus Architecturae Religiosae Europeae, saec. IV-X (CARE-Hispania), Mainake XXXI, 229-242.

RODRÍGUEZ, A. y RODÀ, I., 2007, (eds.), Murallas de ciudades romanas en el Occidente del Imperio. Lucus Augusti como paradigma. Actas del Congreso Internacional celebrado en Lugo (26-29. XI.2005), Lugo.

RODRÍGUEZ-PASCUA, M. A., PÉREZ, R., MARTÍN, F., GINER, J. L., y SILVA, P. G., 2012, Efectos arquitectónicos del terremoto de Lorca del 11 de mayo de 2011. Neoformación y reactivación de efectos en su Patrimonio Cultural, Boletín Geológico y Minero de España 123/4, 487-502.

RODRÍGUEZ-PASCUA, M. A., PÉREZ, R., MARTÍN, F., GINER, J. y SILVA, P. G., 2013, Arqueosismología: una nueva fuente de datos sísmicos y una herramienta para la protección del patrimonio, Ciencia y Arte 4, 53-69.

RODRÍGUEZ-PASCUA, M. A., GINER, J., SILVA, P. G., PÉREZ, R., PERUCHA, M. A., ELEZ, J., BARDAJÍ, T., ROQUERO, E., SÁNCHEZ, I. y MORÍN, J., 2019, Evidencias arqueosismológicas en el yacimiento arqueológico de Idanha-a-Velha (Portugal), en I. SÁNCHEZ y J. MORÍN (eds.), De ciuitas Igaeditanorum a Laŷdāniyya. Paisajes urbanos de Idanha-a-Velha (Portugal) en épocas tardoantigua y medieval, BAR International Series 2943, Oxford, 189-204.

SÁ, A., 2007, Ciuitas Igaeditanorum: os deuses e os homens, Idanha-a-Nova.

SALIDO, J., 2013, El abastecimiento de grano a las ciudades hispanorromanas. Producción, almacenaje y gestión, Archivo Español de Arqueología 86, 131-148.

SALVADO, J., 1983, As muralhas e a torre de Idanha-a-Velha, Idanha-a-Nova.

SÁNCHEZ, I., 2014, Topografía cristiana de las ciudades hispanas durante la Antigüedad tardía, BAR International Series 2606, Oxford.
SÁNCHEZ, I. y MORÍN, J., 2014, Idanha-aVelha. Portugal. 1. El episcopio de Egitania en época tardoantigua, Madrid.

SÁNCHEZ, I. y MORÍN, J., 2015, Nueva lectura arqueológica del conjunto episcopal de Egitania (Idanha-a-Velha, Portugal), Madrider Mitteilungen $56,39-428$.

SÁNCHEZ, I. y MORÍN, J., 2016, Un nuovo approccio archeologico al gruppo episcopale di Egitania nella Tarda antichità (Idanha-aVelha, Portogallo), XVI Congresso Internazionale di Archeologia Cristiana Roma, 22-28 settembre 2013 Costantino e i Costantinidi: l'innovazione costantiniana, le sue radici e i suoi sviluppi, Roma-Ciudad del Vaticano, 149-162.

SÁNCHEZ, I. y MORÍN, J. (eds.), 2017, Arqueología no invasiva. Proyecto IdaVe-Egitania. Un laboratorio para el estudio de la Vega Baja de Toledo, Madrid.

SASTRE DE DIEGO, I., 2017, Guía Arqueológica. Mérida Cristiana, Mérida.

SCHATTNER, T. G., 2009, Römische Spolien in Toledo, en T. G. SCHATTNER y F. VALDÉS (eds.), Spolien im Umkreis der Macht/Spolia en el entorno del poder, Maguncia, 91-150.

ULBERT, T., 2003, Iglesia de Valdecebadar, Olivenza, Badajoz, en P. MATEOS y L. CABALLERO (eds.), Repertorio de arquitectura cristiana en Extremadura. Época tardoantigua y altomedieval, Anejos de AEspA XXIX, Mérida, 95-98.

UTRERO, M. A., 2012, A finales del siglo IX e inicios del x. Entre asturianos y mozárabes, Asturias entre visigodos y mozárabes, en L. CABALLERO, P. MATEOS Y C. GARCÍA DE CASTRO, C. (eds.), Asturias entre visigodos $y$ mozárabes, Madrid, 125-145.

UTRERO, M. A., 2017, Modelos arquitectónicos y decorativos a inicios del siglo $\mathrm{x}$. Algunas certezas y varias hipótesis, Arqueología y Territorio Medieval 24, 185-206.

UTRERO, M. A. y SASTRE DE DIEGO, I., 2012, Reutilizando materiales en las construcciones de los siglos VII-X. ¿Una posibilidad o una necesidad?, 
Anales de Historia del Arte, vol. 22, núm. especial (II), 309-323.

TORRES, C., 1992, A Sé-catedral da Idanha, Arqueología Medieval 1, 169-178.

VELOSA, A. L., COROADO, J., VEIGA, M. R., ROCHA, F., HUGHES, J. J. y GOLD, B., 2007, Characterisation of roman mortars from Conimbriga with respect to their repair. Materials Characterization, Conference: EMABM Euroseminar on Microscopy Applied to Building Materials 10, 58, 1208-1216.

VENTURA, A. y PIZARRO, G., 2010, El Aqua Augusta (acueducto de Valdepuentes) y el abastecimiento de agua a Colonia Patricia Corduba: investigaciones recientes (2000-2010), Las técnicas y las construcciones en la ingeniería romana. V Congreso de las Obras Públicas Romanas, Madrid, 177-203.

VIVES, J., 1963, Concilios visigóticos e hispanoromanos, vol. I, Barcelona-Madrid.

WOLFRAM, M. y SASTRE DE DIEGO, I., 2015, Élites romanas cristianas en Lusitania: ¿Cuál fue su papel en la creación de un nuevo paisaje rural religioso?, XVIII CIAC. Centre and periphery in the ancient world, S. 15. The transformation of the town and countryside in Late Antiquity, Mérida, 1899-1902. 